\title{
Electrohydrodynamic drying of food: new insights from conjugate modeling
}

Thijs Defraeye ${ }^{a, b}$, A. Martynenko ${ }^{3}$

${ }^{a}$ Empa, Swiss Federal Laboratories for Materials Science and Technology, Laboratory for Biomimetic Membranes and Textiles, Lerchenfeldstrasse 5, 9014 St. Gallen, Switzerland

${ }^{b}$ Empa, Swiss Federal Laboratories for Materials Science and Technology, Multiscale Studies in Building Physics, Überlandstrasse 129, 8600 Dübendorf, Switzerland

${ }^{3}$ Department of Engineering, Dalhousie University, Agricultural Campus PO Box 550 Truro, Canada

\begin{abstract}
Electrohydrodynamic (EHD) drying is a non-thermal technology with promising perspectives to dehydrate heatsensitive materials such as foods. With EHD drying, corona discharge is used to generate airflow, which enhances convective drying of the food product. Further development and upscaling of this technology are hindered by a lack of insight both the airflow and the dehydration process inside the material during drying. This study is the first to develop a conjugate continuum model which couples EHD-generated airflow directly to the convective heat transfer and moisture removal from the food. For the wire-to-plate configuration with impinging flow, the impact of different geometrical and operational parameters (wire radius, distance to collector electrode, emitter voltage) on the EHDdriven airflow and resulting drying kinetics is quantified. The fruit drying time is found to increase linearly with increasing distance between electrodes or increasing emitter electrode radius, but decreases in a non-linear way with increasing voltage between the electrodes. For other emitter-collector configurations, where airflow passes around the fruit, such as wire-to-mesh, wire-to-plate, wire-to-wires and wire-to-parallel plates, significant differences in drying kinetics were quantified. Such configurations provide better perspectives towards upscaling to dry large amounts of products uniformly. Of all tested configurations, the wire-to-mesh configuration provided the highest drying rate. Placing the fruit on a mesh also showed to be advantageous since the fruit can be dried more uniformly. The developed conjugate approach has the distinct advantage that the impact of EHD process parameters and geometrical configurations on the drying rate can be quantified very swiftly. Such modeling approach is thereby a valuable tool for further optimization of EHD drying technology towards industrial implementation.
\end{abstract}

This document is the accepted manuscript version of the following article: Defraeye, T., \& Martynenko, A. (2018). Electrohydrodynamic drying of food: new insights from conjugate modeling. Journal of Cleaner Production, 198, 269-284. https://doi.org/10.1016/j.jclepro.2018.06.250

This manuscript version is made available under the CC-BY-NC-ND 4.0 1icense http://creativecommons.org/1icenses/by-nc-nd/4.0/ 
Keywords: Electrohydrodynamic, computational fluid dynamics, dehydration, airflow, corona discharge, COMSOL

\section{Corresponding author}

- E-mail thijs.defraeye@empa.ch

- Tel. $\quad+41(0) 587654790$

- Fax. $\quad+41446331041$ 


\section{Introduction}

Electrohydrodynamic drying is a promising technology to dry foods convectively without using additional heat (Bajgai et al., 2006; Kudra and Martynenko, 2015; Martynenko and Kudra, 2016; Singh et al., 2012; Zhang et al., 2017). Electrohydrodynamic (EHD) airflow is generated by producing a high voltage difference between an emitter electrode, for example a thin wire or needle, and a grounded collector electrode, such as a plate (Figure 1). Due to the high voltage and the large curvature of the emitter, the air around it is ionized locally and corona discharge is produced. The ions are accelerated by the Coulomb force and move towards the grounded collector electrode. The drift of the ions to the collector and their subsequent collisions with neutral air molecules induce corona (ionic) wind $\left(\approx 10^{-1}-10^{1} \mathrm{~m} \mathrm{~s}^{-1}\right)$. This airflow enhances moisture removal from the wet product by increasing convective mass transfer rates. However, also other mechanisms than the additional convection have been argued to increase the drying rate (Bajgai et al., 2006; Singh et al., 2012; Zhang et al., 2017). Since for drying processes, fluid flow is produced in air - not water - one could argue to call the process electro-aerodynamic (EAD) drying (Defraeye and Martynenko, 2018).

EHD drying is a non-thermal technology. As such, it is particularly suitable to dehydrate heat-sensitive biomaterials (Singh et al., 2012), which are often challenging to dry appropriately (Bando et al., 2017; Bantle and Eikevik, 2014; Horttanainen et al., 2017; Prosapio et al., 2017; Sahoo et al., 2017). Compared to mechanically-generated airflow (e.g. a fan), EHD drying does not induce vibrations, has a shorter response time and requires limited power to generate corona discharge. There is also more flexibility in the size and geometry of the system, as airflow is produced locally, i.e. below each needle, instead of centrally, as with an axial fan. These advantages make EHD a promising alternative drying technology. It has been used to dry food products, amongst others apple (Martynenko and Zheng, 2016), mushrooms (Taghian Dinani and Havet, 2015a, 2015b), banana (Pirnazari et al., 2016), mango (Bardy et al., 2016), carrot (Ding et al., 2015) or wheat (Singh et al., 2015). Working prototypes of EHD dryers have been built (Lai, 2010), but no commercial EHD dryers are available yet, although the technology has been known for several decades. Electrohydrodynamics have also been used in other fields, for example for ionic pumps (solid-state fans, plasma actuators), electrostatic precipitators, propulsion engines, cooling devices, active flow control, electrospinning, printing, solar chimneys and building technology (Adamiak, 2013; Fylladitakis et al., 2014; Ghalamchi et al., 2017). 
Emitter electrode (e.g. wire) - High positive voltage

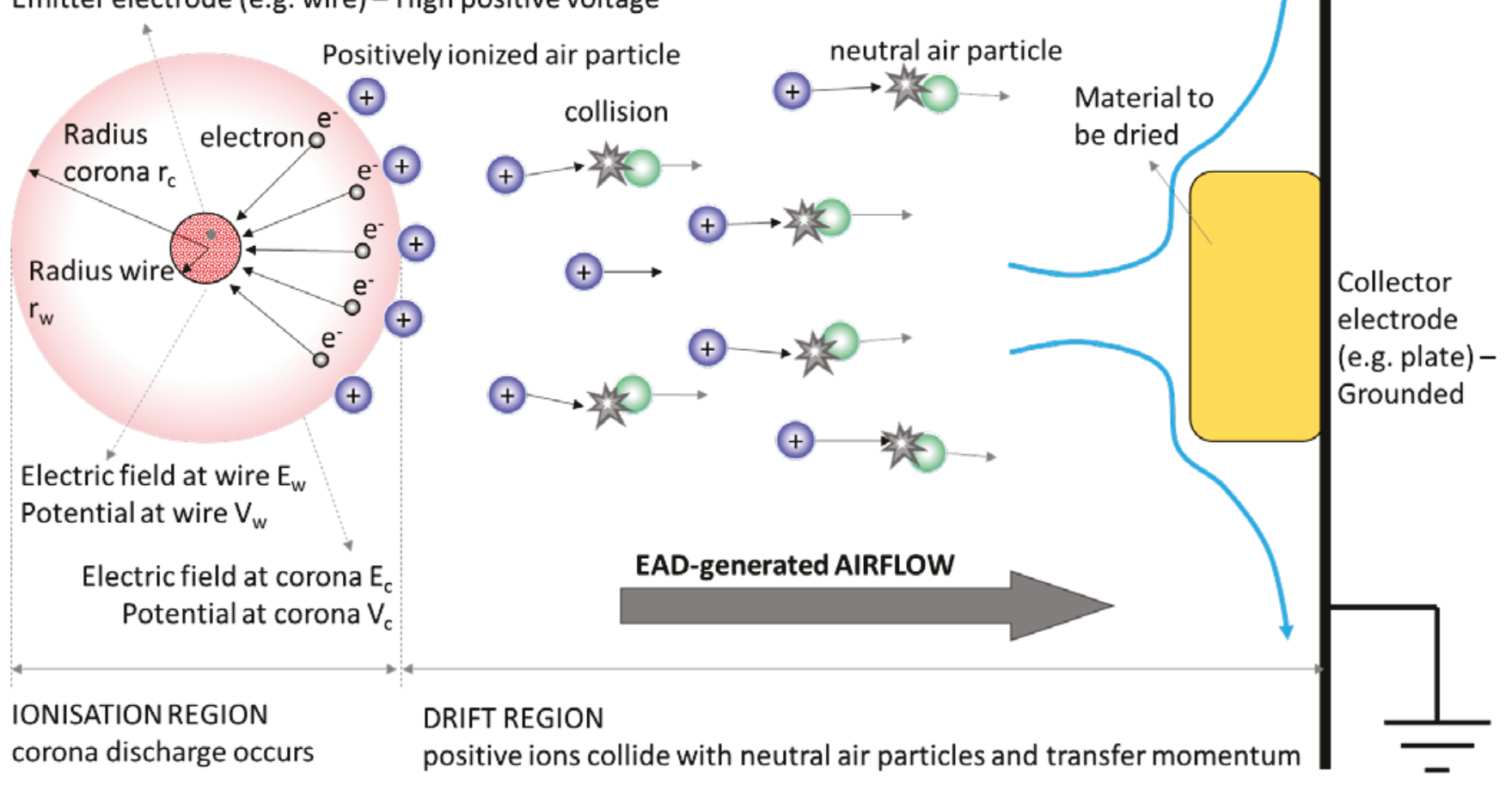

Figure 1. Schematic illustration of EHD airflow generation process for positive corona discharge (not to scale).

The majority of the work on EHD drying has been experimental (Defraeye and Martynenko, 2018). Most of the studies report changes of the bulk moisture content change as a function of time for different applied voltages or corona currents. Product temperatures or (bulk) airflow fields are rarely measured. There are advanced nondestructive techniques available to monitor in real-time the internal moisture content distribution, such as neutron imaging (Defraeye et al., 2016). However, these have not been used for EHD drying. Advanced laser diagnostics, such as particle image velocimetry, have been used to study EHD-generated airflow fields (Kocik et al., 2009; Podlinski et al., 2013). This technique has not been applied for EHD drying studies yet and also does not provide information about moisture or temperature fields in the air. Numerical modeling of the airflow together with the convective drying process using a continuum approach is an alternative to get such information (Caccavale et al., 2016; Curcio et al., 2016; Defraeye, 2014; Defraeye et al., 2012; Defraeye and Radu, 2017; Halder and Datta, 2012). Such a conjugate modeling strategy provides high spatial and temporal resolution, which enables not only to track the internal moisture distribution, temperature and water activity throughout the entire drying process, but also the heat and moisture transport in the airflow (Curcio et al., 2016; Halder and Datta, 2012; Kurnia et al., 2013; Lamnatou et al., 2010, 2009; Marra et al., 2010)). Both surface-averaged and volume-averaged quantities can be extracted, such as the overall moisture loss. Furthermore, extensive parametric evaluations can be performed in relatively short 
timeframes, without being inherently hindered by experimental or biological uncertainty. Despite these advantages, no simulation-based method was developed which explicitly combines EHD-generated flow with drying of fresh foods, such as fruits or vegetables. Several studies however focused on modeling EHD flow (Ayuttaya et al., 2012; Fylladitakis et al., 2014; Ghazanchaei et al., 2015; Ould Ahmedou and Havet, 2009; Oussalah and Zebboudj, 2006). Most studies in EHD drying are focused on evaluation of rather simple wire/needle-to-plate configurations with airflow that impinges onto the food placed on the collector electrode plate (Ding et al., 2015; Esehaghbeygi and Basiry, 2011; Singh et al., 2015; Taghian Dinani and Havet, 2015a; Yang and Ding, 2016). This might not be the optimal configuration to maximize moisture removal when drying multiple products (Defraeye and Martynenko, 2018), as saturation of the air with vapor can occur, as air passes over successive products. This leads to a reduced drying rate of products more downstream. In addition, when multiple wires/needles are considered, multiple streams of air bounce back from the food and interfere with each other. Also here, saturation of the recirculating air with vapor can occur, which is detrimental for the drying rate. To enable industrial upscaling, or at least verify its feasibility, configurations need to be designed that are able to dry large amounts of products uniformly. Moreover, a more detailed knowledge of the EHD airflow generation and especially the coupling to the resulting convective drying process in the product are essential.

In this paper, a 2D numerical continuum model is developed that couples EHD-driven airflow to a dehydration model for fruit. The base case is a wire-to-plate configuration (Figure 2b), where a single fruit is placed on a long plate. The impact of different geometrical parameters (wire radius, distance to collector electrode) and operational parameters (emitter voltage) on the EHD-driven airflow and resulting drying kinetics is evaluated. In addition, the impact of other emitter-collector configurations on the drying kinetics is evaluated. In these configurations, including wire-to-mesh, wire-to-wires and wire-to-parallel plates (Figure 2c), the air flows around the fruit. The aim is to identify which configuration maximizes the fruit drying rate and the dehydration uniformity of the products. To our knowledge, this is the first model that links ionic wind directly to the resulting convective drying process of a food product. 


\section{Materials and methods}

\subsection{Computational model}

A two-dimensional model is made to calculate drying of a single food product, representing a long, rectangular fruit slice. EHD airflow is generated for a wire-to-plate configuration. The computational model includes a cylindrical wire (with radius $r_{w}$ ), i.e. the emitter electrode, onto which a positive high voltage $\left(V_{w}\right)$ is applied. A grounded collector electrode is placed at a distance $d_{e c}$ from the emitter electrode. Ions are assumed to be generated at the emitter electrode. They are accelerated by the Coulomb force in the drift region and are thereby transported to the collector electrode. Under this electrostatic action, airflow is generated, which draws dry air at a temperature $T_{\text {ref }}$ of $20^{\circ} \mathrm{C}$ and a relative humidity $\mathrm{RH}_{\text {ref }}$ of $30 \%$ from the inlet towards the fruit to be dried. These conditions are typical for convective drying of fruit in the ambient environment. Such EHD-driven convective drying, without additional application of heating, is considered a non-thermal technology. The fruit that is dried convectively is a rectangular piece of apple fruit $(\mathrm{L} \times \mathrm{H}=10 \times 5 \mathrm{~mm})$. Apple fruit is chosen as it is a frequently applied model material to study fruit drying and since it has a high commercial value.

\section{Types of configurations}

Three types of configurations are simulated, which are depicted in Figure 2 . The specifications of the simulations are given in Table 1 . Note that the range of EHD process parameters $\left(V_{w}, d_{e c}, r_{w}\right)$ is chosen based on typically used values in previous EHD drying studies (Defraeye and Martynenko, 2018). 
(a) Type 1: Impinging flow configuration without food product

wire-to-plate

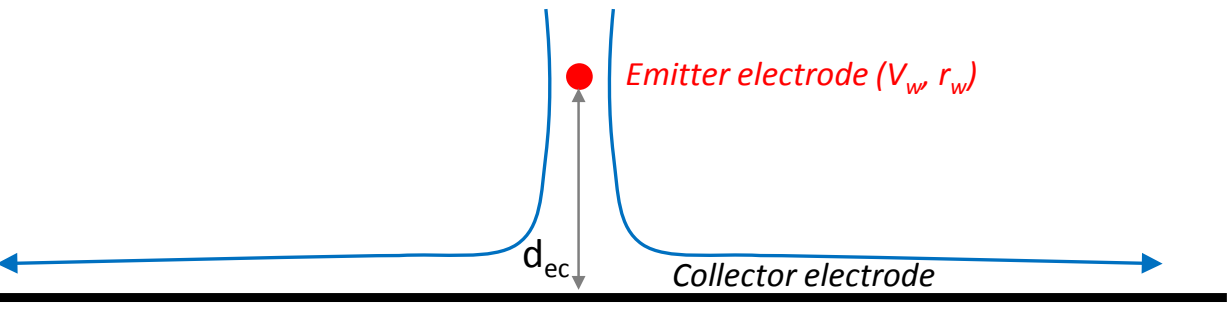

(b) Type 2: Impinging flow configuration with food product

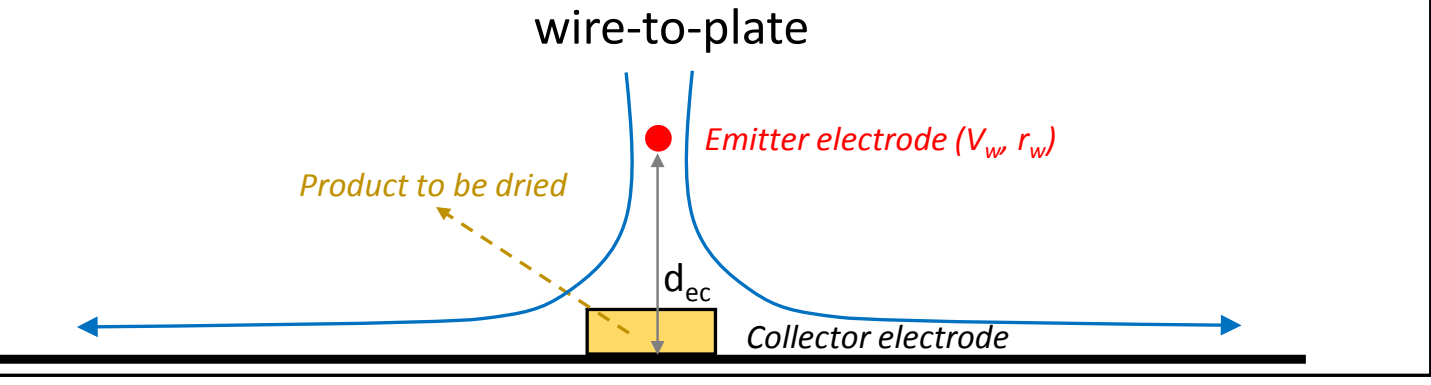

(c) Type 3: Configurations with airflow around the food product

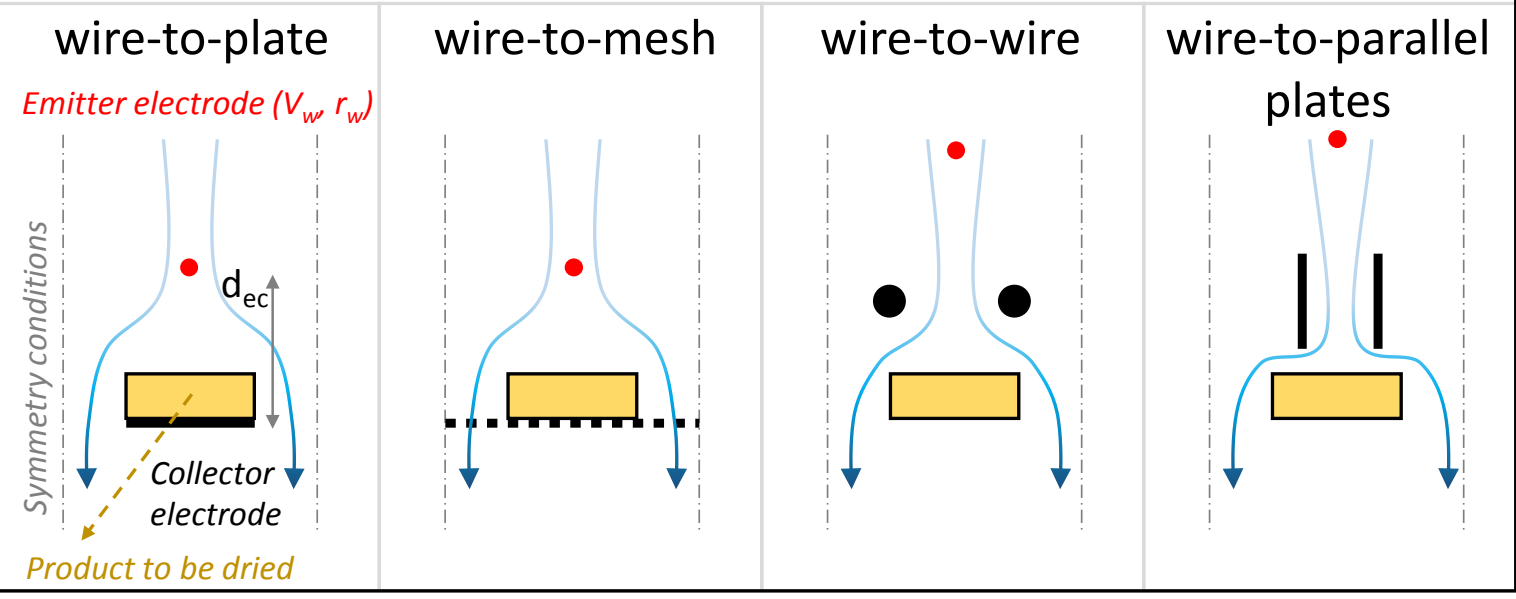

Figure 2. Types of configurations: (a) EHD impinging flow for wire-to-plate configuration (without food product),

(b) EHD drying of a food product for impinging flow for wire-to-plate configuration and (c) EHD drying of a food product for airflow around the food product for various configurations (emitter = red, collector = black; not to scale; legend is the same in each graph; symmetry conditions indicate that multiple products are placed sideways).

As a first type, a wire-to-plate configuration is evaluated for a long solid plate without any fruit being placed on the plate. As such, flow impinges on the plate and is directed sideward to the outlet. This reference case used to get insight in the impact of different process parameters (radius of the wire $r_{w}$, distance between emitter and collector $d_{e c}$ and voltage applied at the wire $V_{w}$ ) and of modeling assumptions on the EHD-driven airflow. For this case, the results are also verified against analytical solutions and experimental data. 
As a second type, a wire-to-plate configuration is evaluated for a long plate, but now a fruit is placed on the plate below the wire. The impact of different process parameters $\left(r_{w}, d_{e c}\right.$ and $\left.V_{w}\right)$ on the EHD-driven airflow but also on the fruit drying kinetics is quantified. This impinging flow configuration is very relevant as most studies in EHD drying looked at similar wire-to-plate or wire-to-needle configurations.

As a third type, configurations with other emitter-to-collector geometries are evaluated. In these cases however, airflow can pass around the fruit. As the moist air is not directed upwards or sideways towards other products, such configurations are considered more optimal for drying multiple products in a uniform way compared to placing them on a large plate. The evaluated configurations have been sourced from EHD flow research and include: wire-to-short plate, wire-to-mesh, wire-to-parallel plates and wire-to-wires. These configurations have not been extensively tested for EHD drying, but could provide enhanced drying kinetics, compared to the impinging flow configuration. For the wire-to-short plate configuration, the fruit is supported by the collector electrode, which is a short metal plate. For all other configurations, the fruit is assumed to lie on a very open-porous wire mesh (with a negligible impact on airflow). In the wire-to-mesh configuration, a metallic (grounded) mesh is assumed, but in wire-to-wires and wire-toparallel plates configurations the mesh is made out of a dielectric material (e.g. plastic). As such, for most Type 3 configurations, the fruit can dry from the bottom surface as well through the mesh.

Table 1. Simulation conditions for different types of configurations. The base case values are indicated in bold. If no value is specified (indicated by a dash), it is taken the same as the base case. The parameter ' $x$ ' in the nomenclature is variable.

\begin{tabular}{|c|c|c|c|c|}
\hline Description & Name & $\begin{array}{l}\text { Wire radius } \\
r_{w}[\mu \mathrm{m}]\end{array}$ & $\begin{array}{l}\text { Distance emitter to } \\
\text { collector electrode } \\
d_{e c}[\mathrm{~mm}]\end{array}$ & $\begin{array}{l}\text { Voltage at wire } \\
\text { (emitter) } \\
V_{w}[\mathrm{kV}]\end{array}$ \\
\hline \multicolumn{5}{|c|}{$\begin{array}{l}\text { Type 1: Wire-to-plate (without fruit) for impinging flow (W2P-IF- } \\
\text { NoFruit) }\end{array}$} \\
\hline Base case & W2P-IF-NoFruit-Base & 250 & 20 & 20 \\
\hline Impact of wire radius & $\begin{array}{l}\text { W2P-IF-NoFruit-rw= } x \\
\mu \mathrm{m}\end{array}$ & $\begin{array}{l}50,100,200,250, \\
300,400,500\end{array}$ & - & - \\
\hline Impact of distance emitter-collector & $\begin{array}{l}\text { W2P-IF-NoFruit-dec }=x \\
\mathrm{~mm}\end{array}$ & - & $5,10,20,40,80$ & - \\
\hline Impact of voltage & W2P-IF-NoFruit-Vw=x & - & - & $12,15,20,25$ \\
\hline
\end{tabular}




\begin{tabular}{|c|c|c|c|c|}
\hline & $\mathrm{kV}$ & & & 30,40 \\
\hline \multicolumn{5}{|c|}{ Type 2: Wire-to-plate (with fruit) for impinging flow (W2P-IF) } \\
\hline Base case & W2P-IF-Base & 250 & 20 & 20 \\
\hline Impact of wire radius & W2P-IF-rw $=x \mu \mathrm{m}$ & $\begin{array}{l}50,100,200,250, \\
300,400,500\end{array}$ & - & - \\
\hline Impact of distance emitter-collector & W2P-IF-dec $=x \mathrm{~mm}$ & - & $10,20,40,80$ & - \\
\hline Impact of voltage & $\mathrm{W} 2 \mathrm{P}-\mathrm{IF}-\mathrm{VW}=\mathrm{x} \mathrm{kV}$ & - & - & $\begin{array}{l}12,15,20,25, \\
30,40\end{array}$ \\
\hline \multicolumn{5}{|c|}{ Type 3: Various configurations for air flow around the fruit (FAF) } \\
\hline Wire-to-short plate & W2SP-FAF & - & - & - \\
\hline Wire-to-mesh & W2Mesh-FAF & - & - & - \\
\hline Wire-to-parallel plates & W2Plates-FAF & - & - & - \\
\hline Wire-to-wires & W2Wires-FAF & - & - & - \\
\hline
\end{tabular}




\section{Computational model}

The computational models for these configurations are specified in Figure 3. The dimensions of the computational domains are taken sufficiently large to avoid an influence from the boundaries on the potential, space charge and airflow fields in the vicinity of the wire (emitter) as well as on the drying process of the fruit. The ionization layer at the vicinity of the wire is not explicitly included as a separate region in the domain, as detailed in section 2.2.1. To be able to compare the efficacy of the different geometrical configurations (Figure 2), similar electrostatic conditions should be applied. This is not that straightforward as all configurations (Type 3) have different collector geometry. To this end, the applied voltage at the emitter was taken the same for all configurations (Type 3, Table 1) and the distance between emitter and collector $d_{e c}$ was chosen in such a way to achieve the same bulk electric field strength $E_{\text {bulk }}\left[\mathrm{V} \mathrm{m}^{-1}\right]$ in each configuration. This parameter is used in several studies and is defined as:

$E_{b u l k}=\frac{V_{w}}{d_{e c}}$

As the voltage is taken the same for all Type 3 configurations, this means that also the distance between the electrodes needs to be the same in order to achieve the same $E_{\text {bulk. }}$. Appropriate grids were built for the air and fruit domains, based on a grid sensitivity analysis. The grid of the base case for type 2 consists of 191298 tetrahedral and quadrilateral finite elements for example (25 574 elements for the fruit domain and 165724 elements for the air domain). A grid refinement towards the electrode boundaries and the air-tissue interface was applied to enhance numerical accuracy and stability, as the largest gradients occur there.

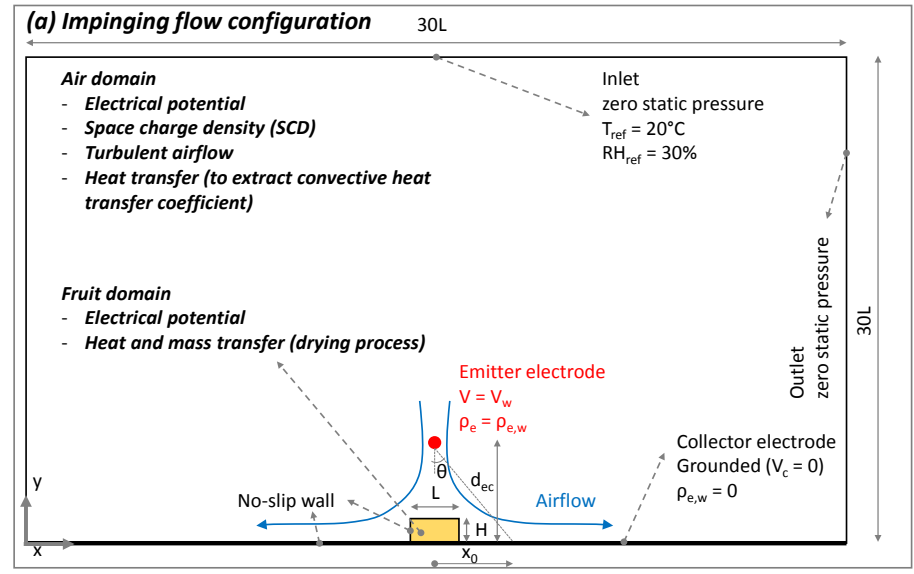

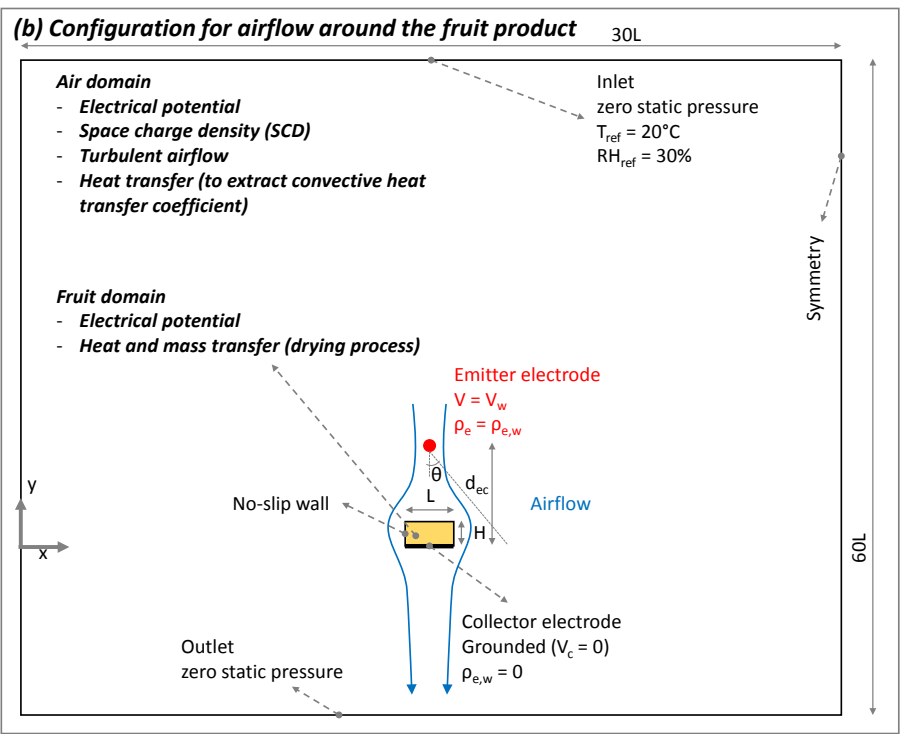


Figure 3. Computational models for EHD drying for impinging (a) and air flow around the fruit (b) configurations, as illustrated for the wire-to-plate configuration (not to scale). 


\subsection{Numerical modeling}

Continuum modeling of EHD drying requires that following phenomena are captured: (1) the electrostatic potential field, (2) the associated charge transport due to ion drift, caused by the corona discharge under the high-voltage field, (3) the resulting airflow generation due to ion movement and collision with neutral air molecules, (4) heat and mass transport in the fruit tissue due to convective, EHD-generated, airflow, leading to dehydration. These individual physics, the corresponding transport equations and the coupling between air and fruit domains are described below. In summary, the numerical procedure first solves for steady-state airflow, generated by the electrohydrodynamic effect. From this airflow field, the convective heat and mass transfer coefficients on the fruit surface are determined. These are used as an input to solve the transient dehydration process of the fruit.

All the used submodels for EHD, the associated airflow and drying process were validated previously by the authors and others (Defraeye et al., 2013; Defraeye and Verboven, 2017; Oussalah and Zebboudj, 2006; Tirumala and Go, 2014). A verification of the EHD model with experimental and analytical data is presented below. Note that existing models are implemented, but the coupling between fruit and airflow was not yet performed for EHD drying. Also note that the boundary and initial conditions are detailed in the Supplementary Material. 


\subsubsection{EHD airflow modeling}

\section{Electrostatics and space charge transport modeling}

The governing equations for EHD-driven flow are well established in several works (Ayuttaya et al., 2012; Fylladitakis et al., 2014; Ghazanchaei et al., 2015; Martynenko and Kudra, 2016; Ould Ahmedou and Havet, 2009; Oussalah and Zebboudj, 2006). The electrical potential $V$ (in [V]) in air and the fruit is described by Poisson's equation:

$\nabla \cdot\left(-\varepsilon_{0} \varepsilon_{r} \nabla V\right)=\rho_{e}$

where $\rho_{e}$ is the space charge density $\left[\mathrm{C} \mathrm{m}^{-3}\right], \varepsilon_{0}$ is the dielectric permittivity of vacuum $\left(8.854 \times 10^{-12} \mathrm{CV}^{-1} \mathrm{~m}^{-1}\right)$, and $\varepsilon_{r}$ is the relative permittivity of the material ( 1 for air and 54 for apple fruit, (Marra et al., 2010)), which is also called the dielectric constant. The electrical potential is linked to the electric field (intensity) $\mathbf{E}\left[\mathrm{V} \mathrm{m}^{-1}\right]$ by:

$\mathbf{E}=-\nabla V$

The resulting electric current in the drift zone (air) is caused by three phenomena: (1) ions that move from emitter to collector electrode due to the presence of the electric field, where this drift is also called conduction; (2) transport of charged particles due to airflow (advection), (3) diffusion of ions. As such, the electric current density J [C $\mathrm{m}^{-2} \mathrm{~s}^{-1}$ ] becomes:

$\mathbf{J}=-\mu_{e} \rho_{e} \nabla V+\rho_{e} \mathbf{u}-D_{i} \nabla \rho_{e}$

where $\mu_{e}$ is the ion mobility in air $\left(1.8 \times 10^{-4} \mathrm{~m}^{2} \mathrm{~V}^{-1} \mathrm{~s}^{-1}\right), D_{i}$ is the diffusivity of the ions $\left[\mathrm{m}^{2} \mathrm{~s}^{-1}\right]$ and $\mathbf{u}$ is the velocity vector for air $\left[\mathrm{m} \mathrm{s}^{-1}\right]$. The conductive term is usually dominant and therefore other two terms are often neglected, resulting in:

$\mathbf{J}=-\mu_{e} \rho_{e} \nabla V=\mu_{e} \rho_{e} \mathbf{E}$

In this study, ion transport is assumed to only occur in the air so not in the fruit. In steady-state conditions, the continuity equation for current density becomes:

$\nabla \cdot \mathbf{J}=0$ 


\section{Airflow modeling}

Conservation of mass, momentum and heat in the air, in stationary state, are modeled by solving the Navier-Stokes equations. The impact of the electric field on the fluid flow is represented by including a volumetric source term $\mathbf{F}_{\mathrm{e}}$ $\left[\mathrm{kg} \mathrm{m}^{-2} \mathrm{~s}^{-2}\right]$ in the momentum equation:

$\rho_{a} \mathbf{u} \cdot \nabla \mathbf{u}=-\nabla p+\mu_{a} \nabla^{2} \mathbf{u}+\mathbf{F}_{\mathbf{e}}$

where $\rho_{a}$ is the air density $\left(1.20 \mathrm{~kg} \mathrm{~m}^{-3}\right.$ at $\left.20^{\circ} \mathrm{C}\right), \mu_{a}$ is the dynamic viscosity of air $\left(1.81 \times 10^{-5} \mathrm{~kg} \mathrm{~m}^{-1} \mathrm{~s}^{-1}\right.$ at $\left.20^{\circ} \mathrm{C}\right)$. The volumetric source term $\mathbf{F}_{e}$, namely the Coulomb (electrophoretic) force, is:

$\mathbf{F}_{\mathbf{e}}=-\rho_{e} \nabla V$

The Coulomb force quantifies the net momentum gain due to the charged particles (ions) that undergo momentumtransfer collisions with neutral air molecules. Some studies also included the dielectrophoretic force, caused by spatial variations in dielectric properties of the air, and the electro-restrictive force due to inhomogeneity in the electric field (Ayuttaya et al. 2012; Singh, Orsat, and Raghavan 2012). For single phase, isothermal fluids, these two terms can be neglected (Dalvi-Isfahan et al., 2016; Heidarinejad and Babaei, 2015).

In order to calculate the convective scalar exchange with the fruit, the convective heat transfer in the air is solved through the heat transfer equation:

$\rho_{a} c_{p, a} \mathbf{u} \cdot \nabla T=-\nabla \cdot\left(-k_{a} \nabla T\right)$

where $c_{p, a}$ is the specific heat capacity of air $\left(1005 \mathrm{~J} \mathrm{~kg}^{-1} \mathrm{~K}^{-1}\right.$ at $\left.20^{\circ} \mathrm{C}\right), k_{a}$ is the thermal conductivity of the air $(0.0258$

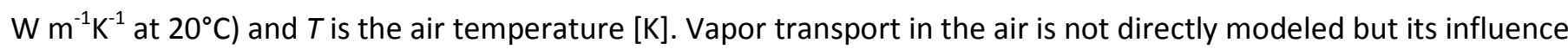
on the drying process is accounted for by using the heat and mass transfer analogy, as detailed further in Supplementary Material.

These equations are solved to obtain EHD-generated airflow and appropriate boundary conditions are specified on the fruit surface (Supplementary Material). Note that, the potential field (Eq. (2)) is also solved inside the fruit. The Navier-Stokes equations for turbulent flow are solved by applying the Reynolds-averaged Navier-Stokes (RANS) approach in combination with the standard $k-\varepsilon$ turbulence model. This turbulence model is still the most commonly 
used model in computational fluid dynamics (CFD) engineering (Casey and Wintergerste, 2000). Wall functions are used to model transport in the boundary layer. The grid resolution in the boundary layer region was made sufficiently dense to have very low values of the dimensionless wall distance ( $\mathrm{y}^{+}$value). The $\mathrm{y}^{+}$values were typically below 5 on the fruit surface. At these low $\mathrm{y}^{+}$values, the boundary layer is actually fully resolved down to the viscous sublayer, by which it corresponds to low-Reynolds number modeling (Defraeye et al., 2013, 2010). Buoyancy effects are not taken into account in the simulations. Long-wave radiation exchange between fruit and the surrounding surfaces is also not included. To solve EHD generated airflow, additional relations are required to specify appropriate boundary conditions for the corona discharge at the emitter electrode. These relations are given in the Supplementary Material. 


\subsubsection{Dehydration modeling of fruit tissue}

To calculate heat and moisture transfer in the fruit tissue during drying, a previously developed model is used

(Defraeye and Verboven, 2017), so only the main characteristics are highlighted here. The main model assumptions are that evaporation is assumed to occur only at the tissue surface and that shrinking and swelling of the tissue are neglected as often assumed in multiphysics modeling of fruit drying (Defraeye, 2014).

\section{Conservation equations}

The following conservation equations for moisture and energy are solved to the dependent variables temperature $T$ $[\mathrm{K}]$ and water potential $\psi[\mathrm{Pa}]:$

$\frac{\partial w_{m}}{\partial \psi} \frac{\partial \psi}{\partial t}+\nabla \cdot\left(-K_{m} \nabla \psi\right)=0$

$h_{l} \frac{\partial w_{m}}{\partial \psi} \frac{\partial \psi}{\partial t}+\left(c_{p, s} w_{s}+c_{p, l} w_{m}\right) \frac{\partial T}{\partial t}+\nabla \cdot\left(-h_{l} K_{m} \nabla \psi\right)+\nabla \cdot\left(-\lambda_{P M} \nabla T\right)=0$

where $w_{s}$ is the dry matter density (solid, $130 \mathrm{~kg} \mathrm{~m}^{-3}$ ) and $w_{m}$ is the moisture content of the tissue $\left[\mathrm{kg} \mathrm{m}^{-3}\right] . K_{m}$ is the moisture permeability of the tissue $\left(8 \times 10^{-16} \mathrm{~s}\right), h_{l}$ is the enthalpy of liquid water $\left[\mathrm{kg}^{-1}\right], \lambda_{P M}$ is the thermal conductivity of the tissue (porous medium, $0.418 \mathrm{~W} \mathrm{~m}^{-1} \mathrm{~K}^{-1}$ ), $c_{p, s}$ and $c_{p, l}$ are the specific heat capacities of dry matter $\left(1634 \mathrm{~J} \mathrm{~kg}^{-1} \mathrm{~K}^{-1}\right)$ and liquid water $\left(4182 \mathrm{~J} \mathrm{~kg}^{-1} \mathrm{~K}^{-1}\right)$, respectively. For $K_{m}$ and the sorption isotherm, the values for the apple cultivar Braeburn are taken (Aregawi et al., 2013).

\section{Constitutive equations}

The enthalpies of liquid water and water vapor, $h_{l}$ and $h_{v}\left[\mathrm{~kg}^{-1}\right]$, are:

$h_{l}=c_{p, l}\left(T-T_{r e f, 0}\right)$

$h_{v}=c_{p, v}\left(T-T_{r e f, 0}\right)+L_{v}$

where $L_{v}$ is the heat of vaporization $\left(2.5 \times 10^{6} \mathrm{~J} \mathrm{~kg}^{-1}\right)$, also called latent heat, which is the energy needed for the phase change from liquid to vapor. $T_{\text {ref,o },}$ is a reference temperature, taken equal to $273.15 \mathrm{~K}\left(0^{\circ} \mathrm{C}\right)$ and $c_{p, v}$ is the specific 
heat capacity of water vapor $\left(1880 \mathrm{~J} \mathrm{~kg}^{-1} \mathrm{~K}^{-1}\right)$. To determine the moisture capacity $C_{m}=\frac{\partial w_{m}}{\partial \psi}$, the sorption isotherm $\left(w_{m}\right.$ vs. water activity $\left.a_{w}\right)$ is required, as well as the relation of the water activity $a_{w}$ to the water potential $\psi$. The latter is given by:

$\psi=\rho_{l} R_{v} T \ln \left(a_{w}\right)$

where $\rho_{l}$ is the density liquid water $\left(1000 \mathrm{~kg} \mathrm{~m}^{-3}\right)$ and $R_{v}$ is the specific gas constant for water vapor $\left(461.52 \mathrm{~J} \mathrm{~kg}^{-1} \mathrm{~K}^{-1}\right)$.

The sorption isotherm equals:

$w_{m}\left(a_{w}\right)=w_{s}\left(\frac{0.15926}{\ln \left(\frac{1.0177}{a_{w}}\right)}\right)^{\frac{1}{0.97014}}$ 


\subsection{Numerical simulations}

This model was implemented in COMSOL Multiphysics (version 5.2a), which is a finite-element based commercial software. For numerical convergence and stability, different physics were solved sequentially. First, the electrical potential and space charge density were solved together as a stationary problem. A parametric sweep for different values of the space charge density at the emitter surface was performed. This was required to determine the correct SCD at which the breakdown electric field strength at the corona surface is reached, which leads to corona formation (section 2.2.1). Linear shape functions were used together with a fully-coupled direct solver, relying on the MUMPS (MUltifrontal Massively Parallel sparse direct Solver) solver scheme. Afterwards, turbulent airflow was solved as a stationary problem, in order to extract the convective transfer coefficient distribution on the fruit surface. The computational fluid dynamics (CFD) module of COMSOL was used, using a segregated solver, relying on the PARDISO (PARallel DIrect sparse SOlver Interface) solver scheme. Finally, the drying process was solved as a transient problem. The partial differential equation interface (coefficient form) was used to calculate the hygrothermal transport in the fruit. Quadratic shape functions were used together with a fully coupled direct solver, relying on the MUMPS solver scheme.

The tolerances for convergence and other solver settings were determined based on sensitivity analysis in such a way that increasing the tolerance further did not alter the solution results anymore. After the steady airflow calculation, the CTCs on the fruit surface were extracted and a drying process for 40 hours was simulated, starting from the specified initial conditions. These simulations applied adaptive time stepping, with a maximal time step of $60 \mathrm{~s}$, as determined from a temporal sensitivity analysis.

\subsection{Drying performance evaluation}

The critical drying time $\left(t_{c r i t}\right)$ is used to compare drying efficiency in a more straightforward quantitative way than just based on drying curves(Defraeye and Verboven, 2017). It is the time needed for the sample to reach the critical moisture content $\left(w_{\text {crit }}\right)$. The latter is defined as the (volume-)averaged moisture content in the sample that corresponds, via the sorption isotherm, to an equilibrium water activity below which no spoilage occurs $\left(a_{w, c r i t}\right)$. For 
dried fruit, this $a_{w, c r i t}$ is about 0.6 (Bonazzi and Dumoulin, 2011). In principle, if the drying process is stopped at $w_{c r i t}$ and the sample is equilibrated at the same or lower water activity, the average final water activity in the tissue will be below $a_{w, c r i t}$. For the present study, $w_{\text {crit }}$ was $37.8 \mathrm{~kg} \mathrm{~m}^{-3}$, leading to a $X_{\text {crit }}$ of $0.29 \mathrm{~kg} \mathrm{~kg}_{\mathrm{dm}}^{-1}$.

With $t_{c r i t}$, only one characteristic value is obtained per drying curve, which facilitates quantifying differences between drying kinetics of different fruits. It is a useful control parameter to decide when to stop a drying process. By stopping the process at the right point in time, over-drying is avoided and energy can be saved. 


\section{Results and discussion}

\subsection{EHD airflow impinging on a plate (without fruit)}

This section focusses on EHD-generated airflow impinging on a large plate without the presence of a fruit. The aim is to (1) verify the obtained model for electrostatics and space charge transport, (2) evaluate the impact of several modeling assumptions, and (3) provide insight in the impact of multiple EHD process parameters $\left(V_{w}, d_{e c}, r_{w}\right)$ on the resulting airflow for the well-known wire-to-plate configuration without fruit.

\subsubsection{Verification of electrostatics}

A common verification of the EHD model is presented, namely a comparison of the current density J (Eq.(5)) right above the collector plate with experimental data (Oussalah and Zebboudj, 2006; Yuen, 2006) and analytical predictions (Figure 4). The electric current density can be described analytically with Warburg's law:

$\mathbf{J}=\mathbf{J}_{\mathbf{0}} \cos ^{m}(\theta)$

where $J_{0}$ is the electric current density below the emitter, $\theta$ is the incident angle (Figure 3 ) with $\tan (\theta)=x_{0} / d_{e c}$, where $x_{0}$ is the distance along the plate and equals 0 in the center of the plate (below the emitter). The exponent $m$ varies usually between 4.5 and 5 (Dalvi-Isfahan et al., 2016), which are both depicted in Figure 4 . The agreement of the simulation data with the analytical equation and experimental results is satisfactory. The electrical current density (J) of the simulations lies within $0.05 \mathrm{~J}_{0}$ of the experimental values of $\mathrm{J}$. 


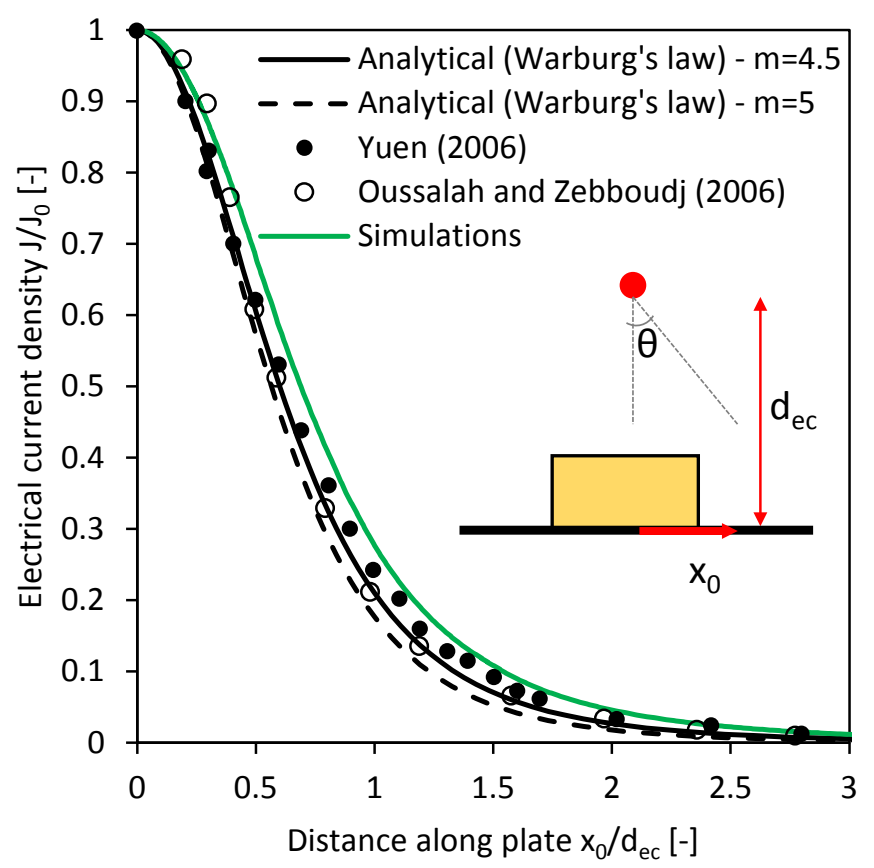

Figure 4. Electrical current density on the plate surface (scaled to the value below the wire $J_{0}$ ) as a function of the distance along the collector electrode ( $x_{0}$, scaled to the distance of the emitter to the collector $d_{e c}$ ) for the simulations, analytical predictions using Warburg's law and experimental data (Oussalah and Zebboudj, 2006; Yuen, 2006).

\subsubsection{Impact of modeling assumptions}

The impact of a few common modeling assumptions on EHD airflow is verified to give modelers insight in which approach to choose when developing the model. First, a case is evaluated where the size of the ionization region is not neglected, but instead the ionization region is explicitly modelled in the following way: instead of taking the wire as the physical boundary in the computational domain (so at $r_{w}$ ) to prescribe the voltage and SCD on, the ionization region $\left(a t r_{c}\right)$ is specified as the physical boundary. The wire is thereby not included in the model. The voltage and size of the ionization region can be calculated from Eqs.(11-13), based on the voltage at the emitter. The resulting radius of the ionization region for the base case $r_{c}$ is $737 \mu \mathrm{m}$ and the applied voltage $V_{c}\left(\right.$ at $\left.r_{c}\right)$ is $17530 \mathrm{~V}$. As a second case, breakdown at the wire is assumed to occur if the surface-average value of the electric field strength over the emitter electrode reaches the breakdown electric field strength, instead of taking the maximal value of the electric field strength at the emitter electrode as the breakdown criterion. Using the surface-average electric field strength value will result in a different SCD at the wire in order to have breakdown, which also needs to be determined 
iteratively. In Table 2 , the resulting average air speed of the total incoming airflow in the domain $\left(U_{\text {ref }}\right)$ and the average convective heat transfer coefficient ( $\mathrm{CHTC}$ ) on the plate are shown for the different cases. The average inflow air speed over all domain boundaries $\left(U_{\text {ref }}\right)$ is calculated based on the total mass flow entering the domain over all domain boundaries, as some air can also enter the domain via the lateral boundaries (outlet in Figure 3).

Table 2. Impact of modeling assumptions on average air speed of the total incoming airflow and surface-averaged convective heat transfer coefficient (CHTC) on collector surface.

\begin{tabular}{|c|c|c|c|c|}
\hline & Air speed & & CHTC & \\
\hline & $\mathrm{m} \mathrm{s}^{-1}$ & $\begin{array}{l}\text { Difference with base } \\
\text { case }\end{array}$ & $\mathrm{W} \mathrm{m^{-2 } \mathrm { K } ^ { - 1 }}$ & $\begin{array}{l}\text { Difference with } \\
\text { base case }\end{array}$ \\
\hline Base case (W2P-IF-NoFruit) & 0.0906 & - & 19.6 & - \\
\hline Ionization region modelled & 0.0950 & $4.9 \%$ & 20.0 & $2.3 \%$ \\
\hline $\begin{array}{l}\text { Average electric field strength } \\
\text { on emitter used }\end{array}$ & 0.0853 & $5.9 \%$ & 19.8 & $0.9 \%$ \\
\hline
\end{tabular}

It is clear that modeling the wire (and neglecting the ionization zone) versus modeling the ionization zone leads to very similar results, given that the correct voltage $V_{c}$ and size of the ionization zone $r_{c}$ are taken. A previous study (Tirumala and Go, 2014) mentions that neglecting the ionization zone is justified if its size is small compared to the electrode gap. In the present study, this is the case $(0.737 \mathrm{~mm} \ll 20 \mathrm{~mm})$. The value of the electric field strength used to determine the SCD iteratively at the emitter electrode (either maximal or surface-averaged), only affects the resulting airflow and heat transfer in a limited way, so both options can be considered.

\subsubsection{Impact of geometrical parameters and operating conditions on airflow and heat transfer}

The impact of EHD process parameters, such as the applied voltage at the emitter $\left(V_{w}\right)$, the distance between emitter and collector $\left(d_{e c}\right)$ and the wire radius $\left(r_{w}\right)$, on the airflow is quantified for the wire-to-plate configuration. In Figure $5 a$, the surface-averaged space charge density over the emitter electrode is shown as a function of $V_{w}, d_{e c}$ and $r_{w}$. In 
Figure $5 b$ and $5 c$, similar graphs are given for the average air speed of the total incoming airflow in the domain $\left(U_{\text {ref }}\right)$ and the surface-averaged convective heat transfer coefficient (CHTC) over the collector plate. Derived correlations based on the data points are also shown. Note that the results with the fruit are also included for reasons of comparison, but they are only discussed later. The Reynolds number, defined based on the average air speed at the domain boundaries $U_{\text {ref }}$ (Figure 5) and the fruit length $\left(L_{f}\right.$ ), ranges from 8-166 (for $V_{w}$ ), 23-136 (for $d_{e c}$ ) and 38-78 (for $\left.r_{w}\right)$. Although these values suggest laminar convective flow, the local air speeds are much higher, as will be discussed below, and airflow can become actually turbulent. 


\section{(a) Space charge density}
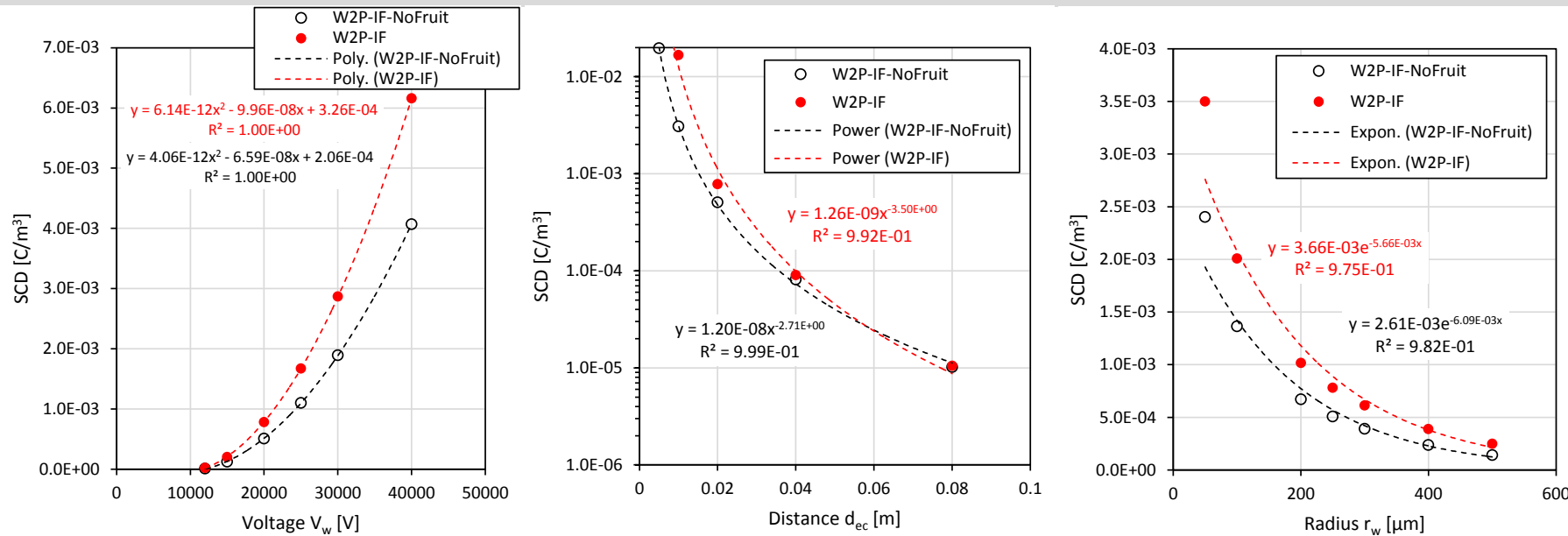

(b) Air speed
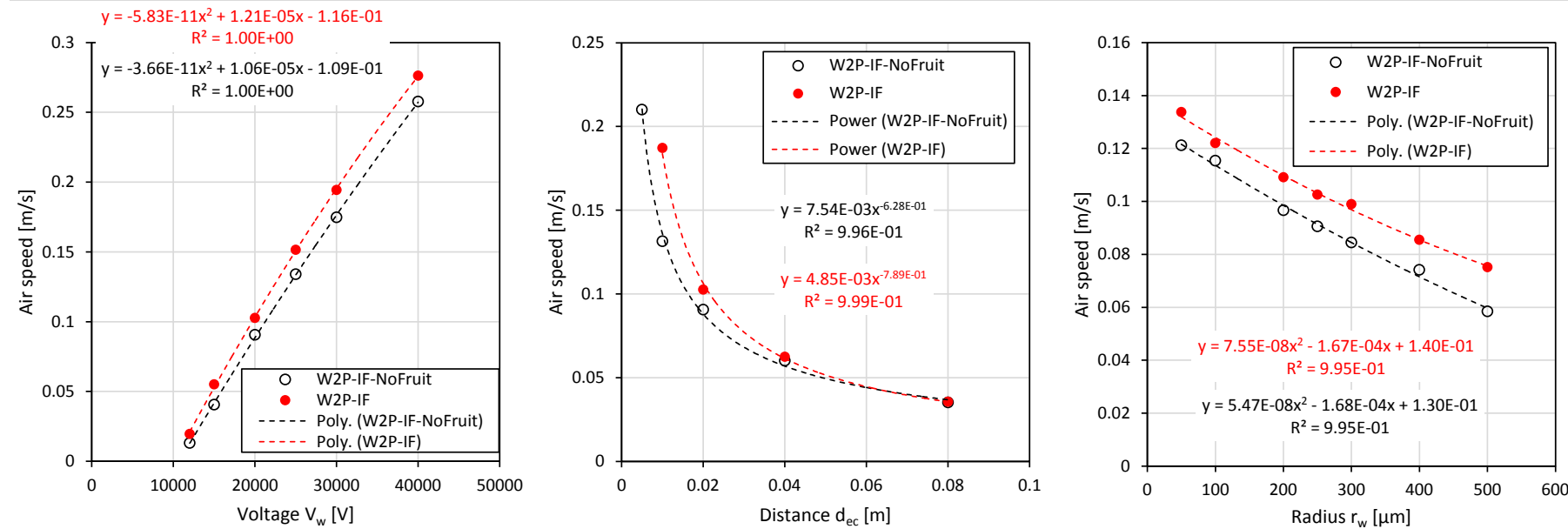

(c) Convective heat transfer coefficient
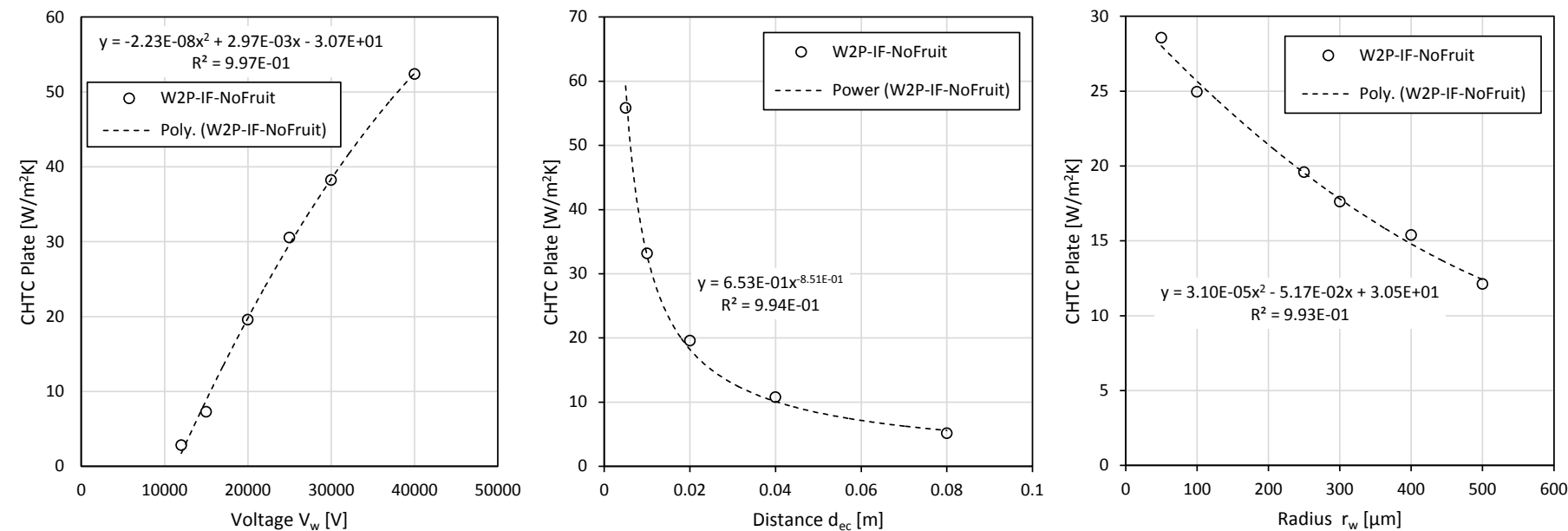

Figure 5. (a) Surface-averaged space charge density (SCD) over the emitter (wire) surface; (b) average inflow air speed over all domain boundaries ( $\left.U_{\text {ref }}\right)$; (c) Surface-averaged CHTC on the collector electrode plate. These quantities are all represented as a function of the voltage at the emitter $\left(V_{w}\right)$, the distance between emitter and collector electrode $\left(d_{e c}\right)$ and the wire radius $\left(r_{w}\right)$ for the wire-to-plate impinging-flow (W2P-IF) configuration. 
Results without (empty dots) and with (filled dots) fruit in the computational model are shown. The base case

parameters are $V_{w}=20 \mathrm{kV}, d_{e c}=20 \mathrm{~mm}, r_{w}=250 \mu \mathrm{m}$

Figure 5 a shows that the space charge density (SCD) clearly has a nonlinear dependency on $V_{w}, d_{e c}$ and $r_{w}$. This SCD at the emitter that is required to initiate corona discharge increases quadratically with increasing $V_{w}$. A power-law correlation approximates the relation of SCD with $d_{e c}$ and $r_{w}$ quite well. The SCD is found to vary several orders of magnitude over the range of $d_{e c}$ that is evaluated. For $r_{w}$, the variation of the SCD is relatively small.

Figure $5 b$ shows that the air speed increases with increasing voltage at the emitter. A quadratic relationship fits slightly better than a linear one. Linear and quadratic relations between air speed and emitter voltage were also found in other studies (Kocik et al., 2009; Zhang et al., 2015). A drastic increase in air speed occurs when the electrode gap is reduced, for which a power-law correlation was found as a good approximation. Changing the wire diameter, for example from $500 \mu \mathrm{m}$ to $50 \mu \mathrm{m}$, only increases the air speed with a factor of about 2 . In general, higher air speeds are achieved at higher voltages, smaller emitter-collector distances and thinner wires. Such numerical quantification of the relation between corona voltage and the resulting air speed serves as a promising alternative for a fast identification of optimal emitter-collector geometrical configurations.

Figure $5 c$ shows that the $\mathrm{CHTC}$ on the collector plate surface has a very similar relation with $V_{w}, d_{e c}$ and $r_{w}$ as the air speed. This is due to the fact that the CHTC for a flat plate is typically related to the air speed with a power-law relation: $\mathrm{CHTC}=\mathrm{a} \cdot \mathrm{U}^{\mathrm{b}}$. Despite the rather low average air speeds $\left(U_{\text {ref }}\right)$ and Reynolds numbers, which suggest laminar flow, the CHTCs are quite high which indicate turbulent flow. The reason is that the local air speeds close to the collector are much higher than the average values over the domain boundaries, namely $\sim 2 \mathrm{~m} \mathrm{~s}^{-1}$ versus $\sim 0.2 \mathrm{~m} \mathrm{~s}{ }^{-1}$, respectively for the base case. If Reynolds numbers would be based on the maximal air speed, they would be at least 10 times higher, which can induce turbulent flow. As such, the impinging flow configuration is very successful for enhancing local scalar (heat or mass) transfer. In summary, to achieve the highest air speed or CHTC, the voltage should be maximized, the electrode gap should be reduced and a thin wire (thus large curvature) should be used.

The validity of using the electric field strength $\left(E_{b u l k}=V_{w} / d_{e c}\right)$ as a simple parameter to characterize the EHD-driven airflow and convective transfer is evaluated. The reason is that $E_{\text {bulk }}$ is often used to characterize and compare different EHD airflow studies (Defraeye and Martynenko, 2018; Esehaghbeygi and Basiry, 2011). To this end, the 
corresponding air speed and CHTC data of Figure 5b-c are presented as a function of the bulk electric field strength in Figure 6. Despite $E_{\text {bulk }}$ being used often in the past, Figure 6 demonstrates that there is no correlation between the $V_{w}, d_{e c}$ and $r_{w}$ datasets. As such, for a particular $E_{b u l k}$, completely different air speeds and CHTCs are obtained, depending on the specific values of $V_{w}, d_{e c}$ and $r_{w}$. This lack of correlation indicates that $E_{\text {bulk }}$ is not a suitable variable to evaluate and compare different configurations.

\section{(a) Air speed}

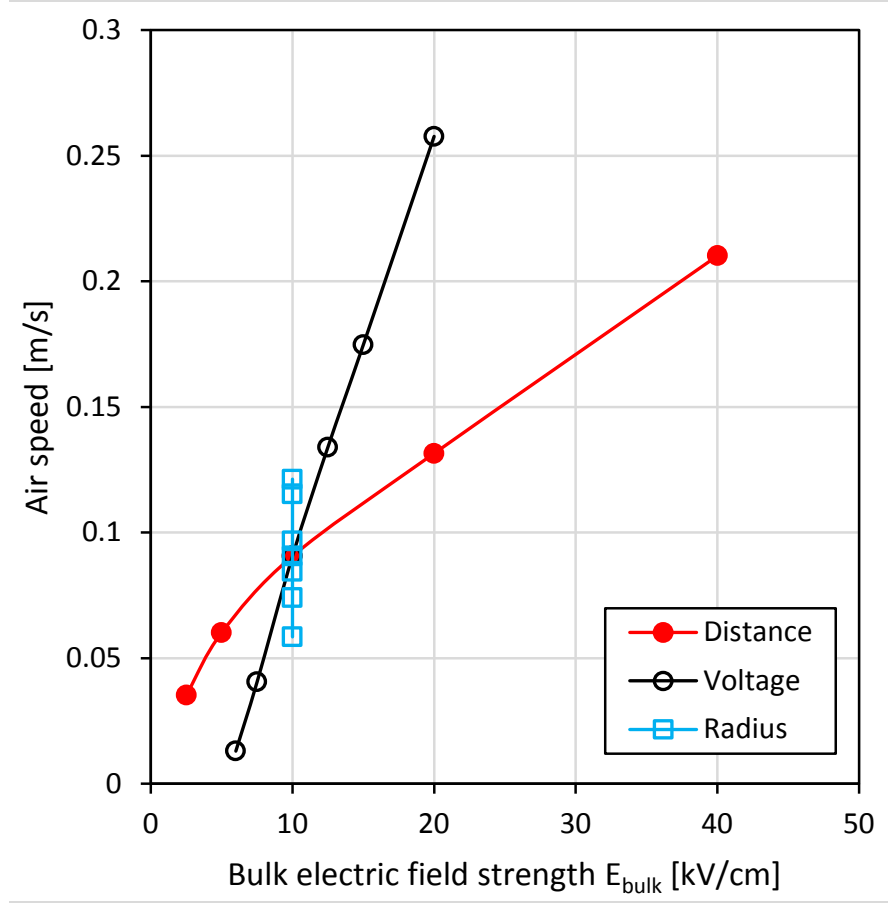

(b) CHTC

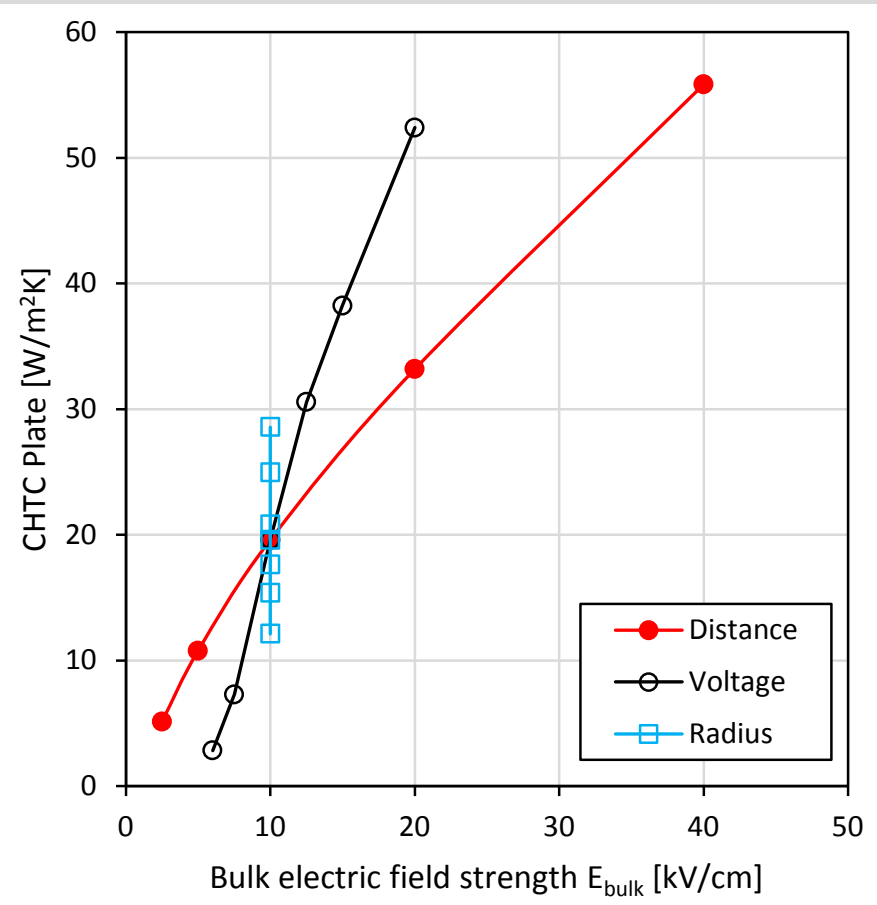


Figure 6. Average inflow air speed over all domain boundaries $\left(U_{\text {ref }}\right)$ and surface-averaged $\mathrm{CHTC}$ on the collector electrode plate as a function of the bulk electric field strength ( $E_{\text {bulk }}$ ) for the wire-to-plate impinging-flow (W2P-IF) configuration (without fruit). Results for different emitter voltages $V_{w}$ (empty dots), distances between the electrodes $d_{e c}$ (filled dots) and wire radii (empty squares) are shown. The base case parameters are $V_{w}=20 \mathrm{kV}, d_{e c}$ $=20 \mathrm{~mm}, r_{w}=250 \mu \mathrm{m}$.

Finally, the ion current between the electrodes $I_{c}[\mathrm{~A}]$ was estimated as follows (Jewell-Larsen et al., 2008):

$$
I_{c}=J_{w} A_{w}
$$

where $J_{w}$ is the surface-averaged ion current density at the emitter [C $\left.\mathrm{m}^{-2} \mathrm{~s}^{-1}\right]$ (Eq.(5)) and $A_{w}\left[\mathrm{~m}^{2}\right]$ is the outer surface area of the wire, which equals $2 \pi r_{w} L_{w}$, where $L_{w}$ is the length of the wire. The average ion current at the emitter is shown in Figure 7 as a function of the voltage at the emitter, assuming a wire length of one meter $\left(L_{w}=1 \mathrm{~m}\right)$. The ion current is small, in the order of a few milliamps per meter of wire. Previous experimental studies (Martynenko and Zheng, 2016; Singh et al., 2017) reported slightly lower currents (below $1 \mathrm{~mA}$ ), which are most likely related to shorter wires or needle electrodes that were used. A quadratic relation between ion current and emitter voltage is found, in correspondence with previous studies (Dalvi-Isfahan et al., 2016; Martynenko and Kudra, 2016).

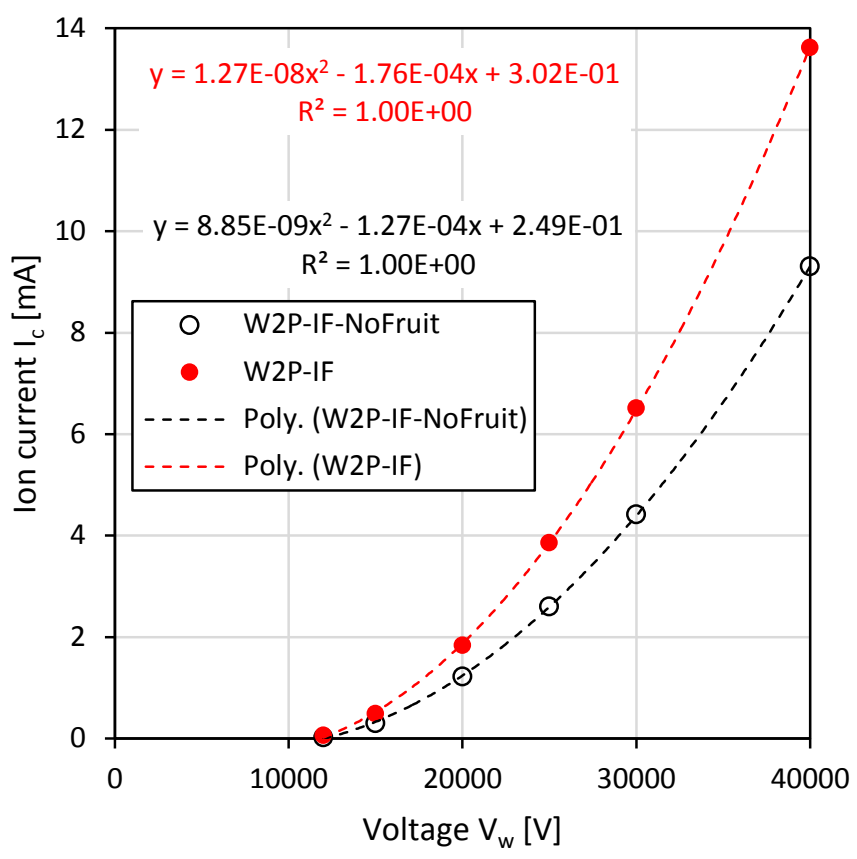


Figure 7. Ion current from emitter to collector ( $I_{c}$, for a 1 meter long wire) as a function of the applied voltage at the emitter for the wire-to-plate impinging-flow (W2P-IF) configuration. Results without (empty circles) and with fruit (filled circles) are shown. 


\subsection{EHD drying of fruit}

\subsubsection{EHD drying for impinging flow on a plate}

For the base case of impinging flow on a plate on which a fruit is placed, the voltage, electric field strength, space charge density, air speed and temperature distribution are illustrated in Figure 8. The complex spatial distribution of these parameters around the emitter electrode and the fruit indicates that they strongly depend on the geometrical configuration that is considered. Note that the heat transport calculation and the resulting temperature distribution are only used to determine the CHTC in a steady-state a-priori calculation (Supplementary Material), so the reported temperature field is not representative for the actual air temperatures during drying.

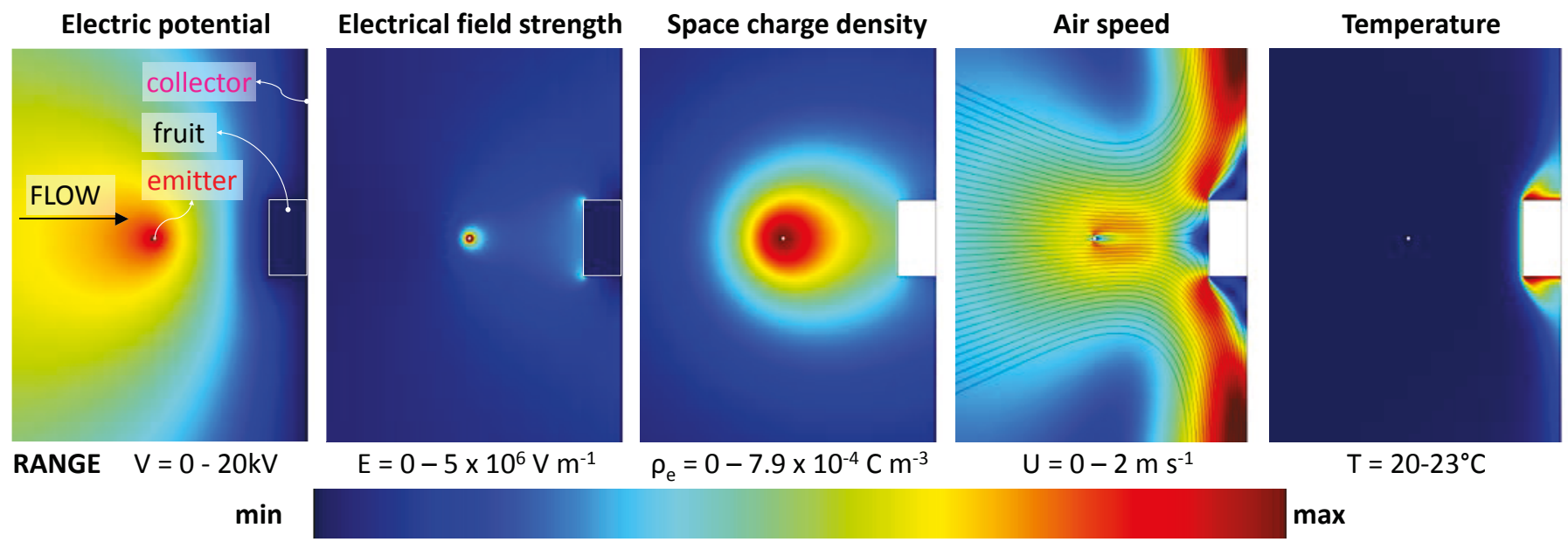

Figure 8. Voltage, electric field strength, space charge density, air speed and temperature distribution for the base case (wire-to-plate configuration for impinging flow with fruit of $5 \times 10 \mathrm{~mm}$ ). The range of the color scale is always depicted for each parameter. Note that these ranges do not always depict the highest calculated values.

The impact of EHD process parameters, such as $V_{w}, d_{e c}$ and $r_{w}$, on the surface-averaged space charge density over the emitter electrode and on the average air speed of the total incoming airflow in the domain $\left(U_{\text {ref }}\right)$ during drying of a fruit for the wire-to-plate impinging-flow configuration was presented earlier in Figure 5a-b. The dependencies of SCD and air speed on $V_{w}, d_{e c}$ and $r_{w}$ with fruit versus without fruit demonstrate very similar trends. In the presence of a fruit, however, slightly higher SCD and air speeds are found, which is attributed to the higher electric permittivity of the fruit. As such, the fruit surface behaves almost as a grounded surface $\left(V_{f s} \ll<V_{w}\right)$. Thereby, the actual distance between the emitter and the grounded surface is smaller, namely $d_{e c}-H$ instead of $d_{e c}$. This results in a stronger electric field and higher air speed. This effect is also the reason that a higher ion current is found in the presence of a 
fruit in Figure 7. In summary, also in the presence of a fruit, higher air speeds are achieved at higher voltages, smaller emitter-collector distances and thinner wires. In Figure 9, the air speed distribution is shown for different voltages, distances between the electrodes and wire radii. It is clear that the jet gets concentrated much more around the emitter when the voltage increases or the wire radius decreases. Over the current range of parameters considered, the air speed distribution changes most drastically when altering the distance between the electrodes.

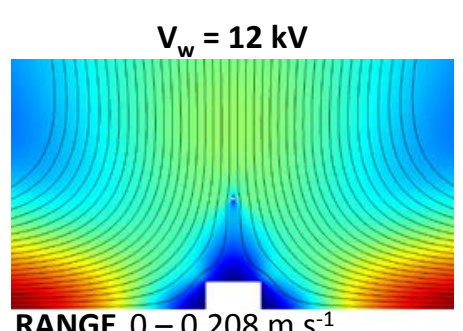

RANGE $0-0.208 \mathrm{~m} \mathrm{~s}^{-1}$
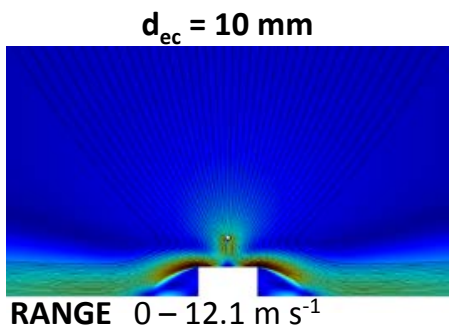

$r_{w}=50 \mu m$

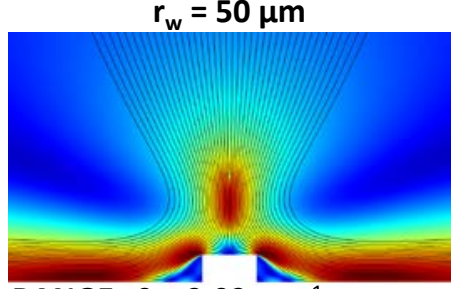

RANGE $0-3.02 \mathrm{~m} \mathrm{~s}^{-1}$ $\min$
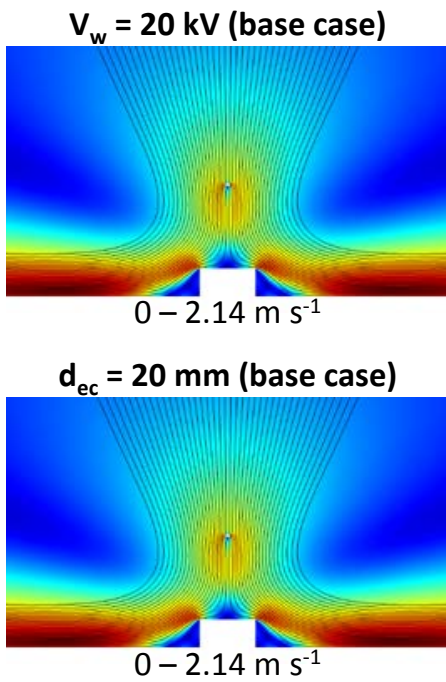

$r_{w}=100 \mu \mathrm{m}$

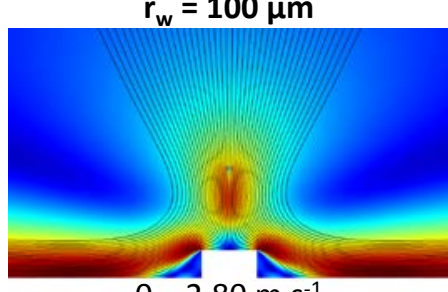

$0-2.80 \mathrm{~m} \mathrm{~s}^{-1}$
$\mathrm{V}_{\mathrm{w}}=30 \mathrm{kV}$

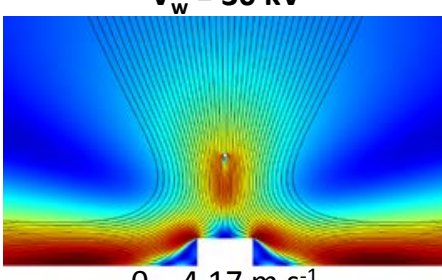

$0-4.17 \mathrm{~m} \mathrm{~s}^{-1}$

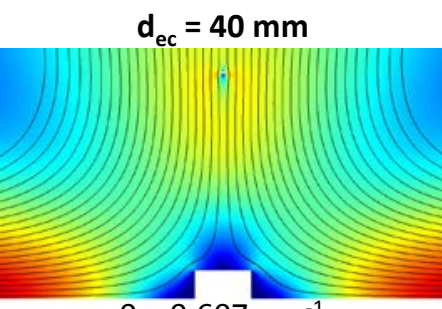

$0-0.607 \mathrm{~m} \mathrm{~s}^{-1}$

$r_{w}=250 \mu \mathrm{m}$ (base case)

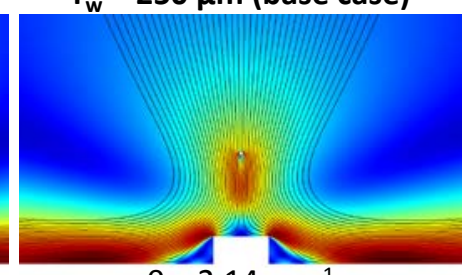

$0-2.14 \mathrm{~m} \mathrm{~s}^{-1}$

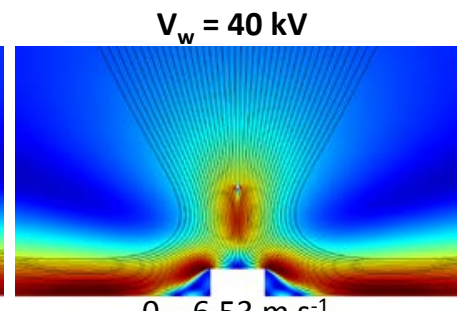

$0-6.53 \mathrm{~m} \mathrm{~s}^{-1}$

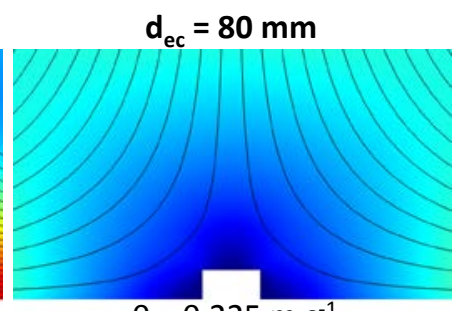

$0-0.225 \mathrm{~m} \mathrm{~s}^{-1}$

$r_{w}=500 \mu m$

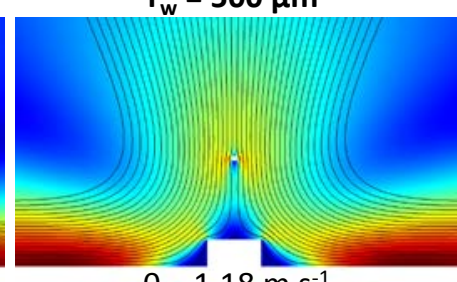
$\max$

Figure 9. Air speed distribution represented as a function of the voltage at the emitter $\left(V_{w}\right)$, the distance between emitter and collector electrode $\left(d_{e c}\right)$ and the wire radius $\left(r_{w}\right)$ for the wire-to-plate impinging-flow configuration (W2P-IF, fruit of $5 \times 10 \mathrm{~mm}$, the base case is indicated). The range of the color scale is always depicted for each voltage.

In Figure 10, the corresponding surface-averaged convective heat transfer coefficient (CHTC) over the fruit surface, along its three exposed surfaces, is given. The dependencies of the CHTC of the fruit surface on $V_{w}, d_{e c}$ and $r_{w}$ show similar trends to the CHTC of the plate surface (without a fruit, Figure $5 \mathrm{c}$ ). The convective transfer coefficients on the 
fruit surface are relatively high and in the same order of magnitude as for forced convective drying of fruits (Defraeye and Radu, 2017). These surface-averaged CHTC give an overall indication of the CHTC magnitude, but actually the CHTC is not constant over the fruit surface. The $\mathrm{CHTC}$ distribution over the fruit surface (half of top surface and entire side surface) is shown in Figure 11 at different voltages. The local $\mathrm{CHTC}$ is scaled here with respect to the surface-averaged $\mathrm{CHTC}$ over the fruit surface. The $\mathrm{CHTC}$ distribution over the fruit surface is clearly dependent on the applied voltage, which causes differences in the air speeds and airflow fields around the fruit.
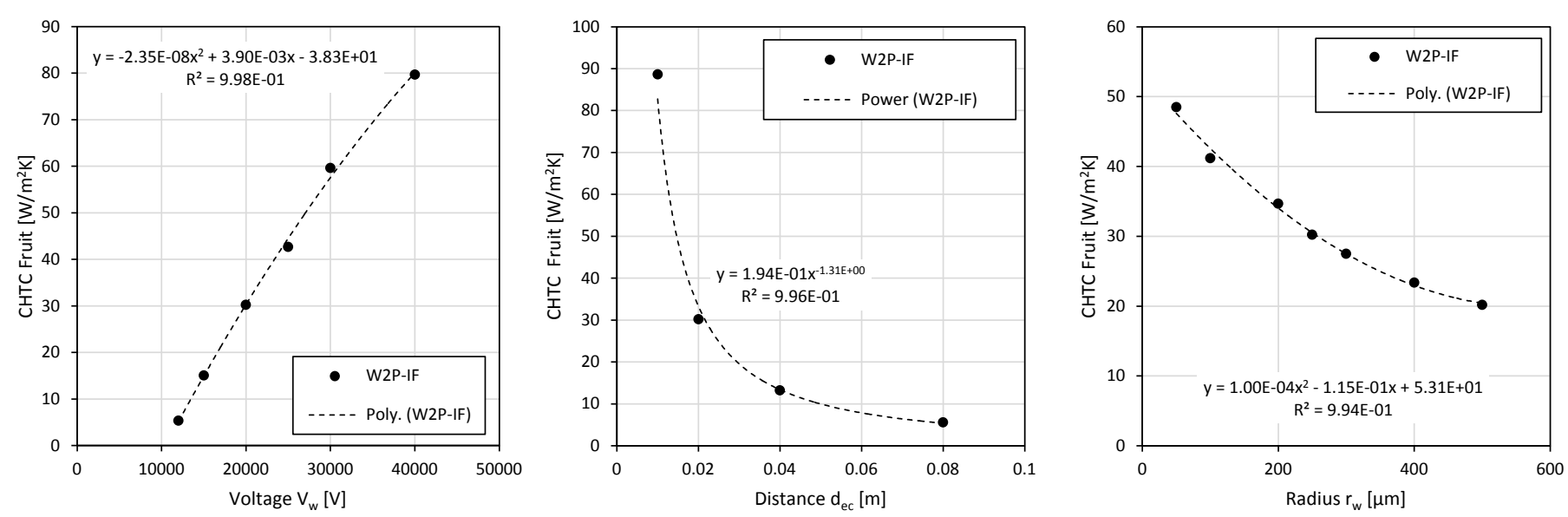

Figure 10. Average CHTC over the fruit surface as a function of the voltage at the emitter $\left(V_{w}\right)$, the distance between emitter and collector electrode $\left(d_{e c}\right)$ and the radius of the wire $\left(r_{w}\right)$ for the wire-to-plate impinging-flow configuration. The base case parameters are $V_{w}=20 \mathrm{kV}, d_{e c}=20 \mathrm{~mm}, r_{w}=250 \mu \mathrm{m}$. 


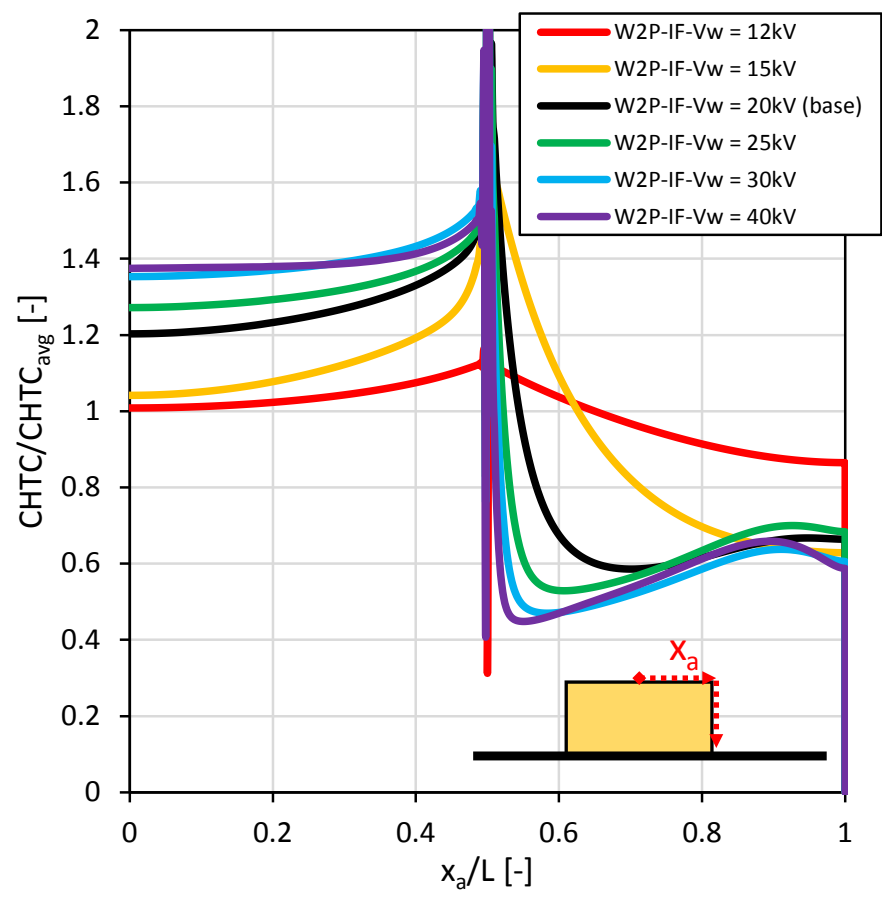

Figure 11. CHTC distribution over the fruit surface (along red dotted line $x_{a}$ ), scaled with the surface-averaged CHTC over the fruit surface, for different voltages for the wire-to-plate impinging-flow (W2P-IF) configuration.

In Figure 12, the dry-base moisture content change $\left(X\left[\mathrm{~kg} \mathrm{~kg}^{-1}\right]\right)$ over time is shown for various values of $V_{w}, d_{e c}$ and $r_{w}$. From these drying curves, the critical drying time is also extracted for all cases (as defined in section 2.4), and is shown in Figure 13. As shown in Figure 10, increasingly higher CHTCs are obtained by increasing the voltage $V_{w}$, decreasing $d_{e c}$ or decreasing $r_{w}$. However, these changes in CTCs do not affect the drying process to the same extent (Figure 12), as the drying time does not seem to reduce proportionally to the increase in CTCs. The reason is that for high CTCs, the resistance to moisture transfer of the boundary layer actually is much smaller than the moisture transport resistance of the fruit tissue. Thereby the internal moisture transfer dominates the drying kinetics at high CTCs, by which a further increase in CTCs clearly has a limited impact on the drying rate. This behavior is especially pronounced with varying voltage. This trend highlights the specific advantage of the present (semi-)conjugate coupling of fruit drying to the airflow, namely that the impact of EHD process parameters on the drying rate can be directly included and quantified. As with the CTCs, the impact of $r_{w}$ on the drying rate is the smallest for the range considered. Figure 13 shows that the critical drying time increases almost linearly with increasing distance between electrodes or increasing wire radius, as indicated by the excellent linear regression. The critical drying time decreases in a very non-linear way with increasing voltage. 
(a) Voltage

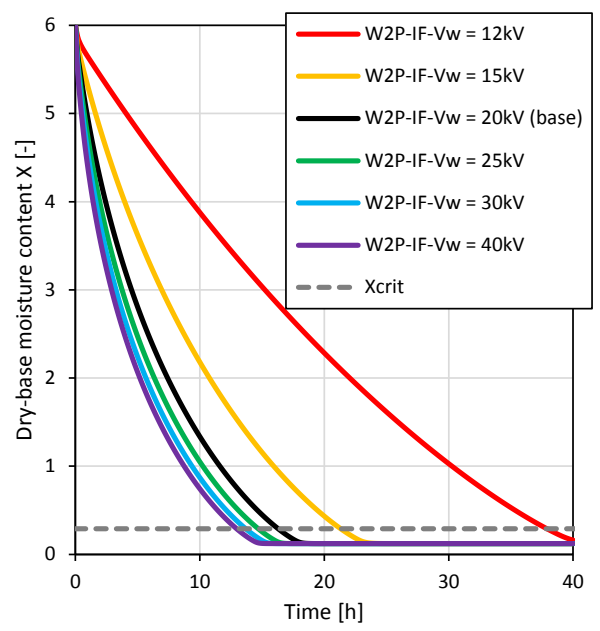

(b) Distance emitter-collector

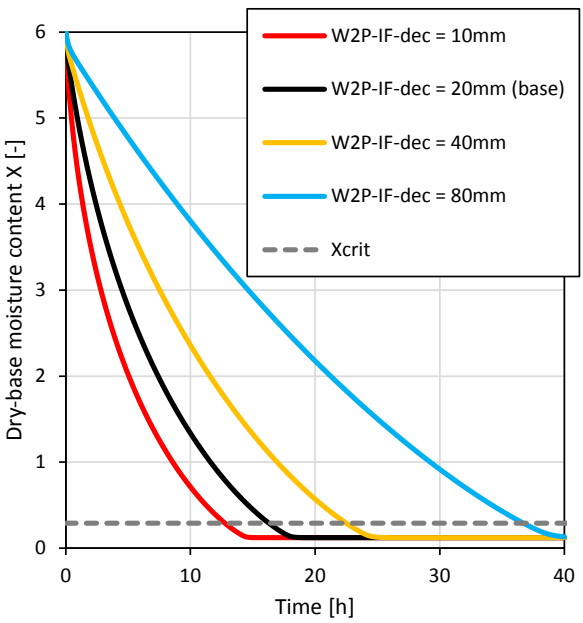

(c) Radius emitter (wire)

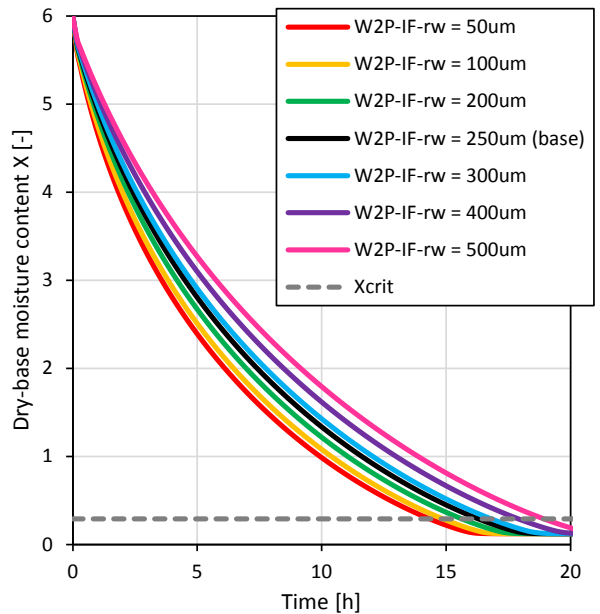

Figure 12. Dry-base moisture content of the fruit $(X)$ as a function of time for different voltages at the emitter $\left(V_{w}\right)$, distances between electrodes $\left(d_{e c}\right)$ and wire radius $\left(r_{w}\right)$ for the wire-to-plate impinging-flow configuration. The base case parameters are $V_{w}=20 \mathrm{kV}, d_{e c}=20 \mathrm{~mm}, r_{w}=250 \mu \mathrm{m}$.

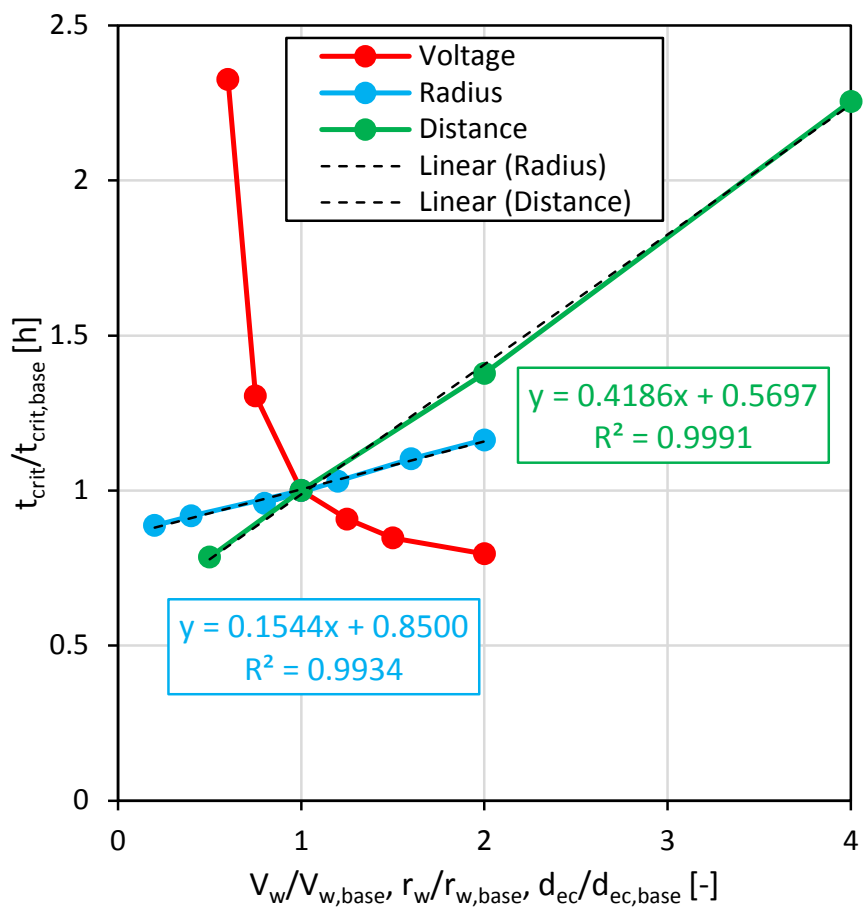

Figure 13. Critical drying time as a function of the voltage at the emitter $\left(V_{w}\right)$, distance between electrodes $\left(d_{e c}\right)$ and wire radius $\left(r_{w}\right)$ for the wire-to-plate impinging-flow configuration. All quantities are scaled with respect to the base case $\left(V_{w}=20 \mathrm{kV}, d_{e c}=20 \mathrm{~mm}, r_{w}=250 \mu \mathrm{m}\right)$. The linear regressions are also given for the radius and distance cases. 
The impact of different geometrical configurations (Figure 2), where air is enabled to flow around the fruit, on the airflow and fruit drying kinetics is quantified. The aim is to identify which configuration is most efficient to dry fruit using EHD airflow within the perspective of industrial upscaling. In Figure 14, the airflow field around the fruit and the water activity inside the fruit (after 5 hours of drying) are shown for all configurations. The magnitude of the surface-averaged CHTC on the fruit surface is also reported. In Figure 15a, the mass loss (dry base moisture content $X$ versus time) is shown for the five different configurations. Note that for the wire-to-plate configurations, the fruit cannot dry from the bottom surface in contact with the collector, which is clear from the water activity profiles as well. For the wire-to-parallel plates and wire-to-wires configurations, the fruit is assumed to lie on a plastic mesh, so air can flow through, by which the fruit can dry from its four sides. In Figure 15b, the air velocity component perpendicular to the outlet is shown for the five different configurations, which is $u$ for the impinging flow configuration and $v$ for the configurations where flow goes around the fruit. This streamwise component is chosen as it is representative for the mass flow going out (or in) of the domain along that boundary.

When comparing both wire-to-plate configurations, the small plate produces a slower drying rate than the infinite plate. This is directly related to the differences between flow fields for impinging flow and flow around the fruit, and the resulting CTCs. The impinging flow configuration has much higher CHTCs, particularly on the windward surface, due to the air jet impinging onto the fruit. This air jet is then directed sideways towards the outlets. The impinging flow configuration is however expected to pose problems when multiple products are dried together on the plate. Since the flow that is produced below the wire is directed sideways, it will gradually pick-up more moisture. This increasingly humid air will reduce the drying rate of fruit located more downstream, which will result in non-uniform drying for different fruits (Defraeye and Martynenko, 2018). Therefore, flow passing around the fruit for the wire-toplate configuration seems a better option as the air is directed over and away from each individual fruit.

The highest drying rate is obtained for the wire-to-mesh configuration. It was better even compared to the impinging-flow wire-to-plate configuration, despite the former having a lower surface-averaged $\mathrm{CHTC}$. The reason is that the wire-to-mesh configuration enables the fruit to dry from the bottom surface as well, in addition to the three other surfaces. In addition to a faster overall drying rate, the product dries also more uniformly (Figure 14). This will also result in less heterogeneity in quality within the fruit. Note however that for a 3D case, for example a fruit cube, 
also drying from the lateral sides (out-of-plane direction) is enabled. As such, these differences in heterogeneity between wire-to-mesh and wire-to-plate will be reduced for a 3D case. The wire-to-mesh configuration remains in any case more suitable to dry many fruits, as they can be placed next to one another on the mesh.

The wire-to-parallel plates and the wire-to-wires configurations dry slower than the wire-to-mesh configuration, which is related to their lower CHTCs. This could be improved by changing $d_{e c}$, which was now taken the same for all cases in order to achieve the same bulk electric field strength (Eq.(1)). However, as shown in Figure 6, $E_{\text {bulk }}$ is not a suitable parameter to compare different geometrical configurations, but it is currently the only one at hand. It is difficult and maybe not possible to define a representative parameter due to the complex dependency of the electric field and the resulting flow field on the geometry. Future studies are required to identify the optimal combination of $d_{e c}$ and $V_{w}$ for each geometry.

When comparing the streamwise air speed (Figure 15b), the maximal air speed is observed downstream of the geometrical center of the fruit for the configurations where air flows around the fruit. For the impinging flow configuration, the maximal air speed is found close to the collector plate. This difference in airflow patterns obviously affects the difference in drying patterns and also creates the difference in volumetric moisture distribution inside of the fruit during drying. The consequences of this uneven airflow distribution on the fruit shrinkage and quality should be the subject of further studies.

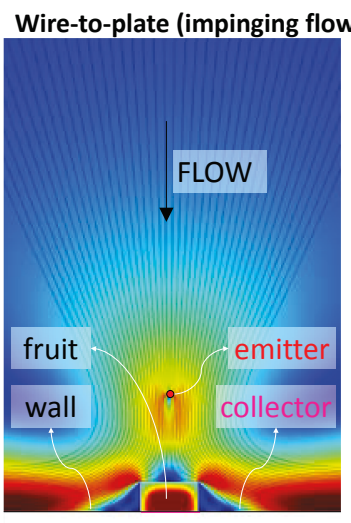

Max. speed $2 \mathrm{~m} / \mathrm{s}$ $\mathrm{CHTC}_{\text {avg }}=30.2 \mathrm{~W} / \mathrm{m}^{2} \mathrm{~K}$

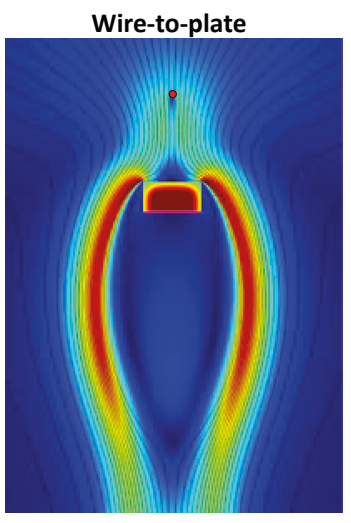

Max. speed $2.5 \mathrm{~m} / \mathrm{s}$ $\mathrm{CHTC}_{\text {avg }}=19.9 \mathrm{~W} / \mathrm{m}^{2} \mathrm{~K}$

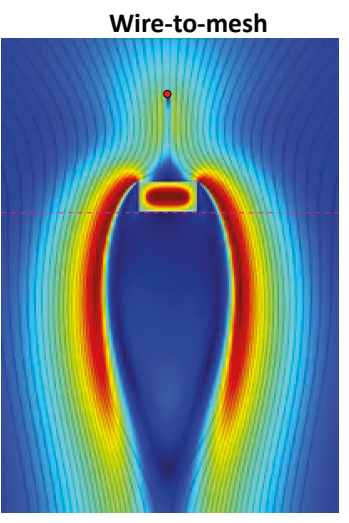

Max. speed $3.5 \mathrm{~m} / \mathrm{s}$ $\mathrm{CHTC}_{\text {avg }}=23.3 \mathrm{~W} / \mathrm{m}^{2} \mathrm{~K}$

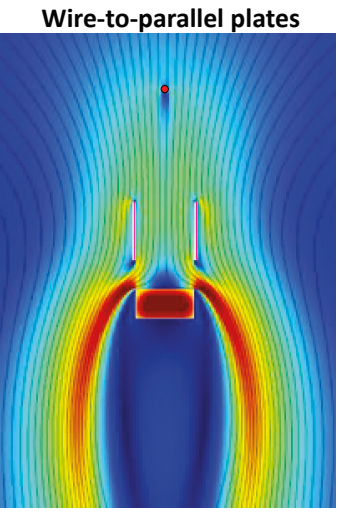

Max. speed $0.85 \mathrm{~m} / \mathrm{s}$ $\mathrm{CHTC}_{\text {avg }}=9.61 \mathrm{~W} / \mathrm{m}^{2} \mathrm{~K}$

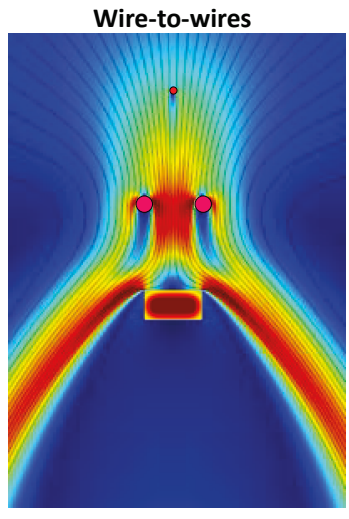

Max. speed $1.5 \mathrm{~m} / \mathrm{s}$ $\mathrm{CHTC}_{\text {avg }}=12.4 \mathrm{~W} / \mathrm{m}^{2} \mathrm{~K}$

SCALE: Air speed (in air domain) - water activity (in fruit domain)

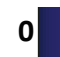
$\max$ 
Figure 14. Airflow field around a fruit of $5 \times 10 \mathrm{~mm}$ and the water activity inside the fruit (range 0-1, after 5 hours of low-temperature drying) for all configurations. The maximal air speed and surface-averaged CHTC on the fruit surface are also reported.

(a) Moisture content

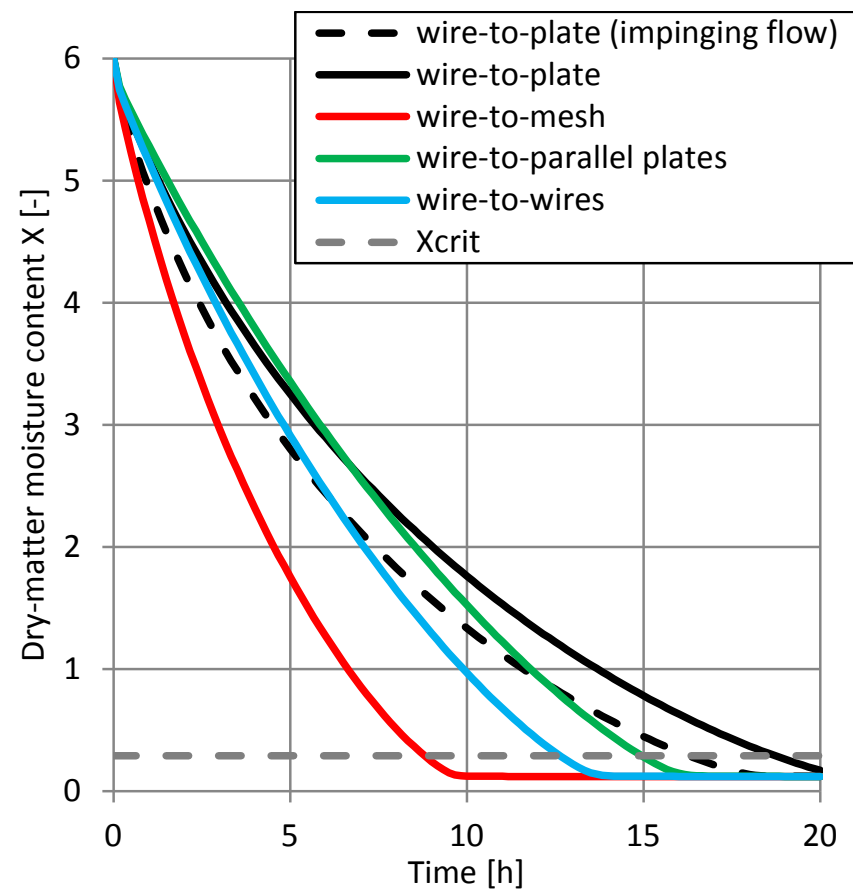

(b) Streamwise air velocity

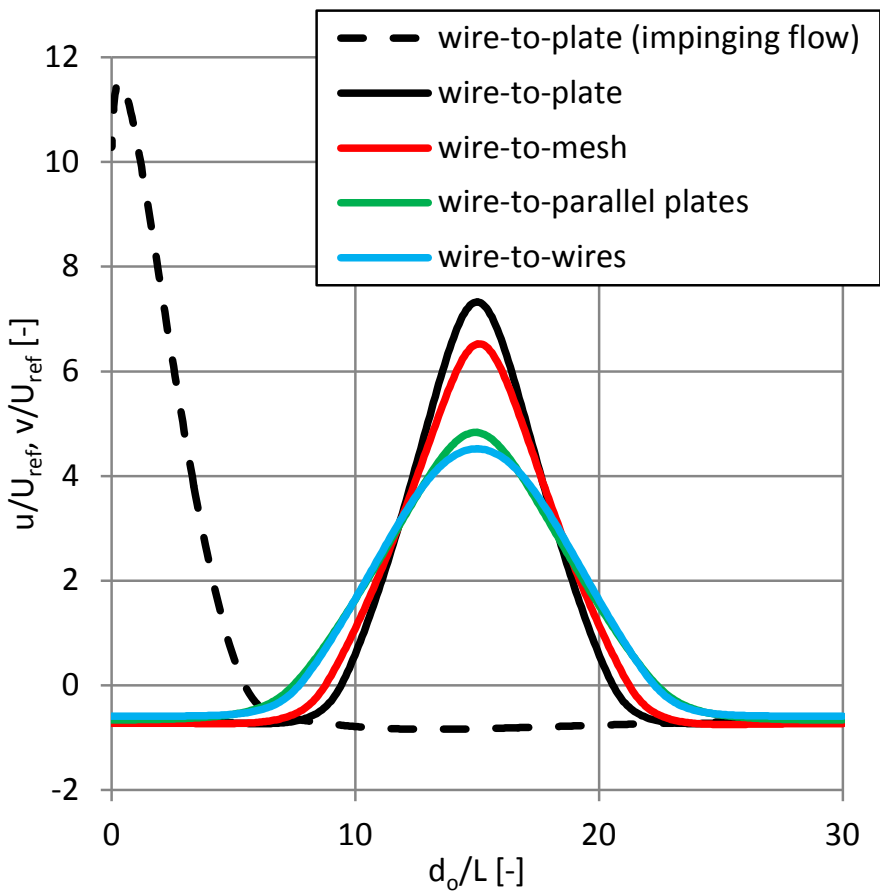

Figure 15. (a) Dry-base moisture content (X) versus time for 5 different configurations; (b) Streamwise air velocity component at the outlet domain boundary (scaled with the average air speed $U_{\text {ref }}$ ) versus distance along outlet $d_{o}$ (scaled with the length of the fruit L). The parameter $d_{0}$ shows the distance along the outlet (at $y=0$ for impinging flow and $x=0$ for flow around the fruit in Figure 2). 


\section{Conclusions}

The electrohydrodynamic drying (EHD) process of a food product was investigated numerically. The aim was to increase our understanding of the airflow around a fruit and of the resulting EHD-driven dehydration process, and to identify the most optimal configurations for industrial upscaling. To this end, the airflow field and resulting convective heat transfer and moisture removal from the fruit were coupled to fruit dehydration in a conjugate way. This study is the first to develop such a conjugate continuum model for EHD drying of fruit, to link ionic wind to the resulting convective drying process. Following conclusions are drawn:

- The bulk electric field strength $\left(E_{\text {bulk }}\right)$, which is the voltage difference over the electrodes $\left(V_{w}\right)$ divided by the distance between them $\left(d_{\mathrm{ec}}\right)$, is not a suitable parameter to evaluate and compare the effect of different geometrical configurations of electrodes.

- The wire electrode does not need to be explicitly included in the numerical model, since also only the ionization region around the wire can be used as a physical boundary in the model.

- The space charge density at the emitter electrode, the approach flow air speed and the convective transfer coefficient at the fruit surface have a non-linear dependency on following EHD process parameters, namely the applied voltage at the emitter $\left(V_{w}\right)$, the distance between emitter and collector $\left(d_{e c}\right)$ and the wire radius $\left(r_{w}\right)$. These dependencies were quantified for the wire-to-plate configuration for impinging flow. For the typical range of EHD process parameters considered, the impact of the wire radius on these quantities was the smallest.

- Regarding the drying kinetics, the critical drying time increases linearly with increasing distance between electrodes or increasing wire radius. The critical drying time decreases in a very non-linear way with increasing voltage between the electrodes.

- Clear differences in the drying kinetics were quantified between impinging flow (wire-to-plate configuration) and configurations enabling flow around the fruit, such as wire-to-mesh, wire-to-short plate, wire-to-wires and wire-to-parallel plates. Impinging flow towards a plate was shown to be not the best solution to achieve fast and uniform drying of the fruit. Of all tested configurations, the wire-to-mesh configuration highest EHD-driven drying rate. Placing the fruit on a mesh showed to be advantageous for drying uniformity, as then fruit can dry from all its surfaces, and also to dry large amounts of fruits together. 
The developed conjugate approach has the clear advantage that the impact of EHD process parameters and geometrical configurations on the drying rate can be directly quantified. Such modeling approach could be a valuable tool to further optimize EHD drying technology towards industrial implementation.

\section{Acknowledgements}

We acknowledge the support of the World Food System Center (WFSC) of ETH Zürich

(http://www.worldfoodsystem.ethz.ch). 


\section{References}

Adamiak, K., 2013. Numerical models in simulating wire-plate electrostatic precipitators: A review. J. Electrostat. 71, 673-680. doi:10.1016/j.elstat.2013.03.001

Aregawi, W., Defraeye, T., Saneinejad, S., Vontobel, P., Lehmann, E., Carmeliet, J., Derome, D., Verboven, P., Nicolai, B., 2013. Dehydration of apple tissue: Intercomparison of neutron tomography with numerical modelling. Int. J. Heat Mass Transf. 67, 173-182. doi:10.1016/j.ijheatmasstransfer.2013.08.017

Ayuttaya, S.S.N., Chaktranond, C., Rattanadecho, P., Kreewatcharin, T., 2012. Effect of ground arrangements on swirling flow in a rectangular duct subjected to electrohydrodynamic effects. J. Fluids Eng. 134, 51211.

Bajgai, T.R., Raghavan, G.S.V., Hashinaga, F., Ngadi, M.O., 2006. Electrohydrodynamic drying - a concise overview. Dry. Technol. 24, 905-910. doi:10.1080/07373930600734091

Bando, K., Kansha, Y., Ishizuka, M., Tsutsumi, A., 2017. Innovative freeze-drying process based on self-heat recuperation technology. J. Clean. Prod. 168, 1244-1250. doi:10.1016/j.jclepro.2017.09.088

Bantle, M., Eikevik, T.M., 2014. A study of the energy efficiency of convective drying systems assisted by ultrasound in the production of clipfish. J. Clean. Prod. 65, 217-223. doi:10.1016/j.jclepro.2013.07.016

Bardy, E., Manai, S., Havet, M., Rouaud, O., 2016. Drying kinetics comparison of methylcellulose gel vs. mango fruit in forced convective drying with and without electrohydrodynamic enhancement. ASME J. Heat Transf. 138, 84504. doi:10.1115/1.4033390

Bonazzi, C., Dumoulin, E., 2011. Quality changes in food materials as influenced by drying processes, in: Tsotsas, E., Mujumdar, A.S. (Eds.), Modern Drying Technology - Product Quality and Formulation. Wiley-VHC Verlag GmbH, Weinheim, Germany, pp. 1-20.

Caccavale, P., De Bonis, M.V., Ruocco, G., 2016. Conjugate heat and mass transfer in drying: A modeling review. J. Food Eng. 176, 28-35. doi:10.1016/j.jfoodeng.2015.08.031

Casey, M., Wintergerste, T., 2000. Special Interst Group on "Quality and Trust in Industrial CFD" Best Practice Guidelines, First edit. ed. ERCOFTAC. 
Curcio, S., Aversa, M., Chakraborty, S., Calabr??, V., Iorio, G., 2016. Formulation of a 3D conjugated multiphase transport model to predict drying process behavior of irregular-shaped vegetables. J. Food Eng. 176, 36-55. doi:10.1016/j.jfoodeng.2015.11.020

Dalvi-Isfahan, M., Hamdami, N., Le-Bail, A., Xanthakis, E., 2016. The principles of high voltage electric field and its application in food processing: A review. Food Res. Int. 89, 48-62. doi:10.1016/j.foodres.2016.09.002

Defraeye, T., 2014. Advanced computational modelling for drying processes - A review. Appl. Energy 131, 323-344. doi:10.1016/j.apenergy.2014.06.027

Defraeye, T., Blocken, B., Carmeliet, J., 2012. Analysis of convective heat and mass transfer coefficients for convective drying of a porous flat plate by conjugate modelling. Int. J. Heat Mass Transf. 55, $112-124$. doi:10.1016/j.ijheatmasstransfer.2011.08.047

Defraeye, T., Blocken, B., Carmeliet, J., 2010. CFD analysis of convective heat transfer at the surfaces of a cube immersed in a turbulent boundary layer. Int. J. Heat Mass Transf. 53, 297-308. doi:10.1016/j.ijheatmasstransfer.2009.09.029

Defraeye, T., Martynenko, A., 2018. Future perspectives for electro-hydrodynamic drying of biomaterials. Dry. Technol. 36, 1-10.

Defraeye, T., Nicolaï, B., Mannes, D., Aregawi, W., Verboven, P., Derome, D., 2016. Probing inside fruit slices during convective drying by quantitative neutron imaging. J. Food Eng. 178, 198-202. doi:10.1016/j.jfoodeng.2016.01.023

Defraeye, T., Radu, A., 2017. Convective drying of fruit: a deeper look at the air-material interface by conjugate modelling. Int. J. Heat Mass Transf. 108, 1610-1622. doi:10.1016/j.ijheatmasstransfer.2017.01.002

Defraeye, T., Verboven, P., 2017. Convective drying of fruit: Role and impact of moisture transport properties in modelling. J. Food Eng. 193, 95-107. doi:10.1016/j.jfoodeng.2016.08.013

Defraeye, T., Verboven, P., Nicolai, B., 2013. CFD modelling of flow and scalar exchange of spherical food products: Turbulence and boundary-layer modelling. J. Food Eng. 114, 495-504. doi:10.1016/j.jfoodeng.2012.09.003

Ding, C., Lu, J., Song, Z., 2015. Electrohydrodynamic drying of carrot slices. PLoS One 10, 1-12. 
doi:10.1371/journal.pone.0124077

Esehaghbeygi, A., Basiry, M., 2011. Electrohydrodynamic (EHD) drying of tomato slices (Lycopersicon esculentum). J. Food Eng. 104, 628-631. doi:10.1016/j.jfoodeng.2011.01.032

Fylladitakis, E.D., Theodoridis, M.P., Moronis, A.X., 2014. Review on the history, research, and applications of electrohydrodynamics. IEEE Trans. Plasma Sci. 42, 358-375. doi:10.1109/TPS.2013.2297173

Ghalamchi, M., Kasaeian, A., Ghalamchi, M., Fadaei, N., Daneshazarian, R., 2017. Optimizing of solar chimney performance using electrohydrodynamic system based on array geometry. Energy Convers. Manag. 135, 261269. doi:10.1016/j.enconman.2016.12.074

Ghazanchaei, M., Adamiak, K., Castle, G.S.P., 2015. Predicted flow characteristics of a wire-nonparallel plate type electrohydrodynamic gas pump using the Finite Element Method. J. Electrostat. 73, 103-111. doi:10.1016/j.elstat.2014.11.003

Halder, A., Datta, A.K., 2012. Surface heat and mass transfer coefficients for multiphase porous media transport models with rapid evaporation. Food Bioprod. Process. 90, 475-490. doi:10.1016/j.fbp.2011.10.005

Heidarinejad, G., Babaei, R., 2015. Numerical investigation of electro hydrodynamics (EHD) enhanced water evaporation using Large Eddy Simulation turbulent model. J. Electrostat. 77, 76-87. doi:10.1016/j.elstat.2015.07.007.

Horttanainen, M., Deviatkin, I., Havukainen, J., 2017. Nitrogen release from mechanically dewatered sewage sludge during thermal drying and potential for recovery. J. Clean. Prod. 142, 1819-1826. doi:10.1016/j.jclepro.2016.11.102

Jewell-Larsen, N.E., Karpov, S. V, Krichtafovitch, I.A., Jayanty, V., Hsu, C.-P., Mamishev, A. V, 2008. Modeling of corona-induced electrohydrodynamic flow with COMSOL multiphysics. Proc. ESA Annu. Meet. Electrost. 1-13.

Kocik, M., Podlinski, J., Mizeraczyk, J., Chang, J.S., 2009. Particle image velocimetry measurements of wirenonparallel plates type electrohydrodynamic gas pump. IEEE Trans. Dielectr. Electr. Insul. 16, 312-319. doi:10.1109/TDEI.2009.4815158

Kudra, T., Martynenko, A., 2015. Energy aspects in electrohydrodynamic drying. Dry. Technol. 33, 1534-1540. 
doi:10.1080/07373937.2015.1009540

Kurnia, J.C., Sasmito, A.P., Tong, W., Mujumdar, A.S., 2013. Energy-efficient thermal drying using impinging-jets with time-varying heat input - A computational study. J. Food Eng. 114, 269-277.

doi:10.1016/j.jfoodeng.2012.08.029

Lai, F.C., 2010. A prototype of EHD-enhanced drying system. J. Electrostat. 68, 101-104. doi:10.1016/j.elstat.2009.08.002

Lamnatou, C., Papanicolaou, E., Belessiotis, V., Kyriakis, N., 2010. Finite-volume modelling of heat and mass transfer during convective drying of porous bodies - Non-conjugate and conjugate formulations involving the aerodynamic effects. Renew. Energy 35, 1391-1402. doi:10.1016/j.renene.2009.11.008

Lamnatou, C., Papanicolaou, E., Belessiotis, V.G., Kyriakis, N., 2009. Conjugate heat and mass transfer from a drying rectangular cylinder in confined air flow. Numer. Heat Transf. Part A 56, 379-405. doi:10.1080/10407780903244353

Marra, F., De Bonis, M.V., Ruocco, G., 2010. Combined microwaves and convection heating: A conjugate approach. J. Food Eng. 97, 31-39. doi:10.1016/j.jfoodeng.2009.09.012

Martynenko, A., Kudra, T., 2016. Electrically-induced transport phenomena in EHD drying - A review. Trends Food Sci. Technol. 54, 63-73. doi:10.1016/j.tifs.2016.05.019

Martynenko, A., Zheng, W., 2016. Electrohydrodynamic drying of apple slices: Energy and quality aspects. J. Food Eng. 168, 215-222. doi:10.1016/j.jfoodeng.2015.07.043

Ould Ahmedou, S., Havet, M., 2009. Effect of process parameters on the EHD airflow. J. Electrostat. 67, 222-227. doi:10.1016/j.elstat.2009.01.055

Oussalah, N., Zebboudj, Y., 2006. Finite-element analysis of positive and negative corona discharge in wire-to-plane system. Eur. Phys. J. Appl. Phys. 34, 215-223. doi:10.1051/epjap:2006063

Pirnazari, K., Esehaghbeygi, A., Sadeghi, M., 2016. Modeling the electrohydrodynamic (EHD) drying of banana slices. Int. J. Food Eng. 12, 17-26. doi:10.1515/ijfe-2015-0005 
Podlinski, J., Niewulis, A., Berendt, A., Mizeraczyk, J., 2013. Pumping effect measured by PIV method in a multilayer spike electrode EHD device for air cleaning. IEEE Trans. Ind. Appl. 49, 2402-2408.

doi:10.1109/TIA.2013.2265214

Prosapio, V., Norton, I., De Marco, I., 2017. Optimization of freeze-drying using a Life Cycle Assessment approach: Strawberries' case study. J. Clean. Prod. 168, 1171-1179. doi:10.1016/j.jclepro.2017.09.125

Sahoo, N.K., Gupta, S.K., Rawat, I., Ansari, F.A., Singh, P., Naik, S.N., Bux, F., 2017. Sustainable dewatering and drying of self-flocculating microalgae and study of cake properties. J. Clean. Prod. 159, 248-256. doi:10.1016/j.jclepro.2017.05.015

Singh, A., Orsat, V., Raghavan, V., 2012. A comprehensive review on electrohydrodynamic drying and high-voltage electric field in the context of food and bioprocessing. Dry. Technol. 30, 1812-1820. doi:10.1080/07373937.2012.708912

Singh, A., Vanga, S.K., Nair, G.R., Gariepy, Y., Orsat, V., Raghavan, V., 2015. Electrohydrodynamic drying (EHD) of wheat and its effect on wheat protein conformation. LWT - Food Sci. Technol. 64, 750-758. doi:10.1016/j.Iwt.2015.06.051

Singh, A., Vanga, S.K.K., Raveendran Nair, G., Gariepy, Y., Orsat, V., Raghavan, V., 2017. Electrohydrodynamic drying of sand. Dry. Technol. 35, 312-322. doi:10.1080/07373937.2016.1170028

Taghian Dinani, S., Havet, M., 2015a. Effect of voltage and air flow velocity of combined convectiveelectrohydrodynamic drying system on the physical properties of mushroom slices. Ind. Crops Prod. 70, 417426. doi:10.1016/j.indcrop.2015.03.047

Taghian Dinani, S., Havet, M., 2015b. The influence of voltage and air flow velocity of combined convectiveelectrohydrodynamic drying system on the kinetics and energy consumption of mushroom slices. J. Clean. Prod. 95, 203-211. doi:10.1016/j.jclepro.2015.02.033

Tirumala, R., Go, D.B., 2014. Comparative study of corona discharge simulation techniques for electrode configurations inducing non-uniform electric fields. J. Electrostat. 72, 99-106. doi:10.1016/j.elstat.2013.12.003

Yang, M., Ding, C., 2016. Electrohydrodynamic (EHD) drying of the Chinese wolfberry fruits. Springer Plus 5, 909-929. 
doi:10.1186/s40064-016-2546-1

Yuen, A.W., 2006. Collector current density and dust collection in wire-plate electrostatic precipitators. University of New South Wales.

Zhang, M., Chen, H., Mujumdar, A.S., Tang, J., Miao, S., Wang, Y., 2017. Recent developments in high-quality drying of vegetables, fruits and aquatic products. Crit. Rev. Food Sci. Nutr. 57, 1239-1255. doi:10.1080/10408398.2014.979280

Zhang, Y., Liu, L., Chen, Y., Ouyang, J., 2015. Characteristics of ionic wind in needle-to-ring corona discharge. J. Electrostat. 74, 15-20. doi:10.1016/j.elstat.2014.12.008 